\title{
Selective Responses to Faces, Scenes, and Bodies in the Ventral Visual Pathway of Infants
}

\author{
Heather L. Kosakowski ${ }^{1 *}$, Michael A. Cohen ${ }^{1,2}$, Atsushi Takahashi ${ }^{1}$, Boris Keil ${ }^{3}$, Nancy \\ Kanwisher $^{1}$, Rebecca Saxe ${ }^{1}$ \\ 1 Department of Brain and Cognitive Sciences, Massachusetts Institute of Technology, 77 \\ Massachusetts Avenue, Cambridge, MA, USA. \\ 2 Department of Psychology and Program in Neuroscience, Amherst College, 220 South \\ Pleasant Street, Amherst, MA, USA. \\ 3 Institute of Medical Physics and Radiation Protection, Department of Life Science \\ Engineering, Mittelhessen University of Applied Science, Giessen, Germany. \\ * Further information and requests for resources should be directed to and will be fulfilled by \\ the lead contact, Heather L. Kosakowski (heatherlkosakowski@gmail.com; @ heatherlkos).
}

\section{Summary}

Three of the most robust functional landmarks in the human brain are the selective responses to faces in the fusiform face area (FFA), scenes in the parahippocampal place area (PPA), and bodies in the extrastriate body area (EBA). Are the selective responses of these regions present early in development, or do they require many years to develop? Prior evidence leaves this question unresolved. We designed a new 32-channel infant MRI coil and collected high-quality functional magnetic resonance imaging (fMRI) data from infants (2-9 months of age) while they viewed stimuli from four conditions - faces, bodies, objects, and scenes. We find that infants have face-, scene-, and body-selective responses in the location of the adult FFA, PPA, and EBA, respectively, powerfully constraining accounts of cortical development.

\section{Introduction}

The human mind is not homogenous and equipotential but structured, containing a set of highly specialized mechanisms for processing particular domains of information, from perceiving faces to understanding language to thinking about other people's thoughts ${ }^{1}$. Much of this domainspecific structure of the mind is mirrored in the functional organization of the brain, which features cortical regions selectively engaged in processing these content domains ${ }^{1}$. How does this functional organization arise over development? Is our cognitive and neural machinery built slowly, over years of experience, or is much of that structure already present early in development? Here, we approach this question by asking whether the domain-specific organization of high-level visual cortex is already present in young infants.

A number of prior fMRI studies in children have argued that category-selective regions of the ventral visual pathway (VVP), including the fusiform face area (FFA) ${ }^{2}$, parahippocampal place area $(\mathrm{PPA})^{3}$, and extrastriate body area $(\mathrm{EBA})^{4}$, develop very slowly, increasing in size throughout childhood and into adolescence ${ }^{5-11}$. But those studies have not tested children younger than 3 years of age, focusing primarily instead 
on children ages 7 and up. To understand development, we need to know if category selective responses are present in infants. Research using electroencephalography (EEG), magnetoencephalography (MEG), and functional near-infrared spectroscopy (fNIRS) have reported neural responses in the infant brain to faces ${ }^{12-14}$, scenes ${ }^{14}$, and bodies ${ }^{15,16}$, but these studies have used only a single control stimulus type, providing only weak tests of selectivity. Further, these methods lack the spatial resolution to determine if the recorded responses are coming from the same cortical locations as the adult FFA, PPA, and EBA. Only two publications have reported fMRI responses in the VVP of awake infants, one in humans $(n=6)^{17}$ and one in macaques $(n=3)^{18}$. These studies observed an adultlike spatial organization of responses to faces in both species ${ }^{17,18}$ and scenes in human infants ${ }^{17}$. However, the activated regions did not show selective responses, instead responding as strongly to objects as to faces or scenes. Thus, no prior studies have reported selective responses in infants to faces, bodies, or scenes that can be localized to the FFA, PPA, or EBA, respectively.

Taken together, these results have led to a hypothesis that infant cortex is organized by featurebased protomaps that extend from primary sensory areas to higher-level cortical regions ${ }^{18-22}$ and that selective responses to specific visual categories, such as faces, scenes, and bodies develop later based on extensive visual experience with that category. This hypothesis predicts that category-selective responses will emerge in regions of cortex that correspond to overlapping protomap features. For example, because faces tend to be foveated and have substantial low spatial frequency and curvilinear content, the FFA will develop in a region of the protomap that responds preferentially to foveal, low spatial frequency, and curvilinear input. Conversely, scenes extend into the periphery and tend to have high spatial frequency and rectilinear content, so the PPA will develop in a peripheral region of the protomap that overlaps with preferences for high spatial frequency and rectilinear content. Importantly, this hypothesis predicts that responses to features of the protomaps, such as retinotopy, curvilinearity, rectilinearity, and spatial frequency, would arise earlier in development than responses to high-level visual categories such as faces, scenes, and bodies ${ }^{20}$.

Much of the evidence for this hypothesis comes from the absence of category-selective responses in VVP as measured with fMRI ${ }^{17,18}$. We reasoned to the contrary that the FFA, PPA, and EBA might be category-selective, but have gone undetected in prior infant studies due to limitations in the quality and amount of data obtained. It is extremely difficult to obtain high quality fMRI data from awake infants because they have short attention spans ${ }^{23}$, cannot follow verbal instructions, and tend to move in the scanner. Further, the tools used for collecting and processing infant data are less advanced than those for adults. To test our hypothesis, we scanned a much larger number of infants and devised a variety of technical innovations to increase both the quantity and quality of data we could obtain (see Fig. 1a \& Methods). To sustain infants' attention, we used engaging, colorful stimuli depicting faces, bodies, objects, and scenes (Fig. 1b). We recruited 87 infants and were able to collect usable fMRI data from 52 of them (2.1-9.7 months; see Methods). The primary results reported here reflect data from 26 infants scanned on a second-generation custom 32-channel infant head coil (referred to here as Coil 2021) with a higher signal-to-noise ratio (SNR) than an equivalent adult coil ${ }^{24}$ and MR-safe headphones that provided better hearing protection, enabling the collection of infant fMRI data at a resolution commonly used for adult 90 studies. 


\section{Results}

Do human infants have face-, scene-, or body-selective responses in the VVP? As an initial exploratory analysis, we first conducted voxelwise whole-brain analyses testing for higher responses to each condition of interest (i.e., faces, scenes, and bodies) compared to objects. Individual subject activation maps and group random effects analyses $(n=23)$ found higher responses to faces than objects in the fusiform gyrus, higher responses to scenes than objects in the parahippocampal gyrus, and higher responses to bodies than objects in lateral-occipital cortex (Fig. 2), areas that correspond to the location of the FFA, PPA, and EBA in adults. While suggestive, these responses did not reach thresholds for statistical significance when correcting for multiple comparisons across the whole brain.

\section{FFA, PPA, and EBA are category-selective in infancy.}

To test the anatomical location and selectivity of these regions more directly and stringently, we next conducted a standard fROI analysis using previously described anatomical parcels that constrain localization of the FFA, PPA, and EBA in adults ${ }^{25}$. To accommodate the imperfect registration of infant functional data to adult anatomical templates, we uniformly increased the size of each parcel by a small amount (see similar fROI results for unexpanded parcels in Table $\mathrm{S} 1)$. We then selected the top $5 \%$ of voxels in each parcel, in each participant that had a numerically greater response to the preferred category corresponding to that parcel (e.g., faces for the FFA) than to objects, in one subset of the data. Then, in independent data in the same participant, we quantified the response in those voxels to each of the four conditions using linear mixed effects models (see Methods). In the main dataset, 19 infants had enough data to be included in this analysis.

This fROI analysis identified voxels in the FFA parcel where responses to faces were significantly greater than the response to each of the other three categories (all $P s<0.001$; Fig. 3a; Table S1), scene responses in the PPA parcel that were significantly greater than each the other three categories (all $P s<0.01$; Fig. 4a; Table S1; though not higher than baseline), and body responses in the EBA parcel that were significantly greater than each of the other three categories (all $P s<0.05$; Fig. 5a; Table S1).

How much of each cortical parcel contains the predicted pattern of selectivity? We conducted the same fROI analysis in each parcel, varying the number of voxels selected from the top $1 \%$ of voxels to $100 \%$ of voxels. In the FFA, we observe a selective response to faces in held-out data when selecting anywhere from $1 \%$ to $30 \%$ of voxels (Fig. 3a), suggesting that face-selective responses in infant FFA spans about $217.5 \mathrm{~mm}^{3}$ of cortical territory. In the PPA, the scene response is greater than the response to all other conditions even when $100 \%$ of voxels are included in the analysis (Fig. 4a), suggesting that scene responses in infant PPA covers at least $1320 \mathrm{~mm}^{3}$. Finally, in the EBA, the response to bodies is selective only when the top 1-, 2-, or 5percent of voxels are selected (Fig. 5a), or approximately $131.6 \mathrm{~mm}^{3}$. (Note that these areas are estimates in the volume, not on the cortical surface.) Thus, selective responses in infant fROIs are robust to analytic parameters for voxel selection; and face, scene, and body selective responses are present in the locations predicted from prior studies of adults. 
Are face, scene and body selective responses found distinctively in their predicted locations? In each of the three parcels (FFA, PPA, and EBA), we selected voxels using all three contrasts (faces>objects, scenes>objects, bodies>objects) at each threshold for voxel selection (top $1 \%$ to $100 \%$ ), and then computed the selectivity of these voxels in held out data. In the FFA parcel, there were many face-selective voxels, and no scene- or body-selective voxels (Fig 6a). In the PPA, there were many scene-selective voxels and no body- or face-selective voxels (Fig 6b). In the EBA, both the bodies>objects and faces>objects contrasts identified reliable voxels (Fig 6c); however, while the top $1 \%-5 \%$ of body-responding voxels were body-selective (significantly higher than faces, objects, and scenes each independently), most face-responding voxels in the EBA parcel responded to both faces and bodies. In the EBA parcel as a whole, the majority of voxels responded to faces, bodies, and objects more than to scenes (Fig 5a).

Taken together, these results indicate that the FFA, PPA, and EBA are present in infancy, in the same anatomical location and with a selective response to the same preferred category as adults.

\section{Higher quality fMRI data led to observation of selective responses.}

Why do we find face-, scene-, and body-selective responses when Deen et al. ${ }^{17}$ did not? The face, body, object, and scene videos used in the present study were a subset of the same videos used in Deen et al., and the average age of the infants across the studies is similar. However, in contrast to Deen et al. ${ }^{17}$ the current study used a new coil (Coil 2021), a different pulse sequence producing higher resolution data, and included data from more subjects; there are also some differences in the analyses. To test which of these factors explained the difference in results between the present study and those of Deen et al., ${ }^{17}$ we analyzed a third dataset we had collected on the first generation custom 32-channel infant head coil (referred to as Coil 2011), before Coil 2021 was built. For all subjects in the Coil 2011 dataset (which did not overlap with the current data, or the data published by Deen et al.), we used the same pulse sequence and coil used by Deen et al. This enabled us to test whether the use of Coil 2021 and/or the higher resolution acquisition sequence could explain the observed difference in results. Indeed, in matched fROI analyses of the Coil 2021 data and the Coil 2011 data $(\mathrm{n}=39)$, we found significant selectivity for faces, places, and bodies in Coil 2021 data but not Coil 2011 data, and a significant Experiment (Coil 2011 vs. Coil 2021) by stimulus condition by fROI interaction (Fig. S3c; $F(6,108)=2.38, \eta^{2}=0.013, P=0.013$ ). These results indicate that it is the new coil and pulse sequence of the current study that enabled us to find selectivity when Deen et al. did not.

\section{Visual statistics are not sufficient to explain category-selective responses.}

Are face- and scene-selective responses in infants driven by low-level visual features of the stimuli? The protomap hypothesis predicts that the region that will develop into FFA initially responds preferentially to low spatial frequency and curvilinear input. In our paradigm, the stimuli with most curvilinear and low spatial frequency input were the object videos and the swirly baseline (Fig. S2). Yet the response to faces in FFA is significantly greater than the response to both baseline and object videos $(P s<0.05$; Table $\mathrm{S} 1)$. Therefore, curvilinearity and low spatial frequency are unlikely to account for the selective response to faces in FFA. 
Similarly, the protomap hypothesis predicts that the region that will develop into PPA initially responds preferentially to high spatial frequency and rectilinear input. In our stimuli, rectilinear input was highest in the object movies (Fig. S2), yet the PPA responded significantly more to scenes than objects. High spatial frequency input was highest in the scene movies, and so might explain early PPA responses. However, one unexpected feature of the PPA response could not be explained by either a response to high spatial frequencies or category selectivity: the response in PPA was similar for scene movies and for the swirly baseline ( $P>0.2$; Table S1), despite scenes containing substantially more high spatial frequency (as well as semantic scene) content. It is research should investigate the optimal stimuli for infant PPA.

In summary, the responses of the FFA and PPA in infants cannot be easily accounted for in terms of lower-level visual features or "protomaps" ${ }^{18,20-22,26-30}$ (see Discussion).

\section{Selectivity observed in some, but not all, high-level visual areas that are selective in adults.}

In addition to the FFA, PPA, and EBA, other occipitotemporal regions exist in adults that respond selectively to faces, scenes, and bodies. Are these regions also present in infants? The occipital face area (OFA) and occipital place area (OPA) are located in lateral occipital cortex (with EBA between them) and are thought to reside earlier in the visual hierarchy than FFA ${ }^{31}$ and $\mathrm{PPA}^{32}$, respectively. Thus, a posterior to anterior development of face- and scene-selectivity would predict that OFA and OPA would acquire characteristic functional specificity prior to FFA and PPA ${ }^{21}$. However, fROI analyses using adult parcels for OFA and OPA, with the same method just described, did not find significant face-selectivity in the OFA or scene-selectivity in the OPA (all $P s>0.05$ except OFA F $>$ S $P=0.004$; Figs. $3 \mathrm{~b} \& 4 \mathrm{~b}$; Table S1).

What about regions thought to reside later in the visual hierarchy, such as the face selective response in anterior temporal lobe (ATL)? An fROI analysis with an adult ATL parcel ${ }^{33}$ found that face responses in infant ATL were selective (all $P s \leq 0.01$; Fig. 3c; Table S1). However, an fROI analysis using an adult parcel for the fusiform body area (FBA), a body-selective region thought to arise later in the neural hierarchy than $\mathrm{EBA}^{34}$, found only numerically but not significantly greater responses to bodies than the other three conditions in the FBA parcel (all $P s>0.05$; Fig. 5b; Table S1). Similarly, the scene response in the retrosplenial cortex (RSC) was numerically but not significantly greater than the response to all of the other conditions ( $\mathrm{S}>\mathrm{F}$ $P=0.3, \mathrm{~S}>\mathrm{B} P=0.1, \mathrm{~S}>\mathrm{O} P=0.02$; Fig. 4c; Table S1).

Thus, we find significantly category selective responses in infant FFA and ATL for faces, PPA for scenes, and EBA for bodies, but not in other regions.

\section{Discussion}

Here we report that the FFA, PPA, and EBA are present in infants, in the same location, and with qualitatively similar selectivities, as adults. Continued development may expand and refine these regions over subsequent years ${ }^{5-11}$, but the existence of category-selective mechanisms in the brain evidently does not require years of visual experience and maturation. 
Our finding of face-, scene-, and body-selectivity in infant FFA, PPA, and EBA differs from the earlier findings of Deen et al. ${ }^{17}$, who found preferential but not fully category selective responses in these regions in infants. The most likely account of this difference is that the current study benefited from the higher quality data afforded by our new infant coil ${ }^{24}$ and the higher resolution pulse sequence.

Our findings inform ongoing debates about cortical development, including the question of how visual experience influences the emergence of functionally selective regions in VVP. These regions appear in approximately the same cortical location in every individual, implying that patches of cortex are predisposed for specific functions. However, the nature of these predispositions is unknown and disputed. On one view, visual cortex is organized at birth into "protomaps": smooth, orthogonal spatial gradients of neurons tuned along low-level visual feature dimensions like retinotopy, spatial frequency, and curvilinearity $18,20-22,26-30$. The natural statistics of early visual experience cause frequent co-activation of neurons with certain responses (e.g., faces are low frequency and curvy, and typically foveated; scenes are high frequency and boxy and experienced in the periphery). Extensive visual experience thus leads to the slow emergence of cortical regions selectively responsive to these stimulus categories in cortical regions already tuned for their low-level correlates. Evidence for this view comes from fMRI studies with macaques. In early infancy ( $\sim 30$ days) V1 and regions that later become faceselective respond similarly to intact faces and pixelated faces ${ }^{18}$. In juvenile macaques ( $\sim 200$ days of age) the response profiles between V1 and face-selective regions begin to differentiate as faceselective regions (but not V1) begin to respond less to pixelated faces ${ }^{18}$.

A key prediction of the protomap hypothesis is that protomaps for spatial frequency and curvilinearity are present across the primate brain prior to functionally specialized responses ${ }^{20}$. However, our infant FFA responses do not have a pattern of response that corresponds to either low spatial frequency or curvilinearity, and our infant PPA responses do not have a pattern of response that corresponds to either high spatial frequency or rectilinearity. Thus, our data place important constraints on the protomap framework. If an underlying protomap combined with visual experience drives selectivity of domain specific regions like the FFA, PPA, and EBA, only a few months of visual experience must be sufficient to acquire that selectivity.

Relatedly, some theorists have proposed that selectivity in cortical regions might emerge in sequence, following the hierarchy of bottom-up visual processing in VVP. On this view, lowlevel representations in early visual cortex might emerge first, followed by mid-level representations in lateral-occipital cortical regions, culminating in higher-level visual representations in the VVP. For example, fMRI studies of infant macaques found that BOLD responses to motion emerged first in $\mathrm{V} 1$, followed by $\mathrm{V} 4$, and then $\mathrm{MT}^{35}$. A feedforward pattern of development has similarly been suggested for VVP such that OFA and OPA would develop prior to FFA and PPA, respectively, because they are presumed to lie earlier in the visual hierarchy ${ }^{36-38}$. (The hierarchical relationship of FBA and EBA is unclear ${ }^{39-43}$.) In contrast to this prediction, we observed scene-selectivity in PPA, but not its "precursor" OPA, and we observed face-selectivity in FFA, but this selectivity did not reach significance in its "precursor" OFA. These results should be interpreted with caution, though, given that null results in infant fMRI are always suspect, and the OPA and OFA are smaller and less robust regions even in adults. 
275 Nevertheless, it is intriguing that our data show no evidence of feedforward hierarchical

276 emergence of category selectivity in VVP in infants.

If not entirely driven by low-level feature protomaps and bottom-up input from earlier visual areas, what else might constrain the development of functionally selective regions in infants? One possibility is that in infants, VVP regions have distinctive preexisting long-range connectivity not only to early visual regions, but also to non-visual regions (e.g., in parietal and frontal cortices). These patterns of connectivity can be used to accurately predict the location of functionally selective regions in infants ${ }^{44}$ and children ${ }^{45}$. Further, these connections exist prior to the emergence of selective responses in at least some cases: for example, patterns of connectivity in pre-readers can be used to predict the future location of the visual word form area when the same child learns to read ${ }^{45}$. As further evidence for connectivity from non-visual areas, the putative VWFA has stronger functional correlations with putative language areas compared to functional correlations between nearby FFA and putative language areas ${ }^{46}$. Finally, congenitally blind humans have auditory and tactile responses in the FFA that are selective for faces ${ }^{47,48}$, and distinctive patterns of resting functional correlation between the "blind FFA" and both visual and nonvisual regions ${ }^{47}$. Thus, we speculate that the location of FFA, PPA, and EBA may be influenced by pre-existing long-range connectivity to both early visual regions and also regions in parietal and frontal cortex.

Many fundamental open questions remain. First, although we found clear evidence of category selectivity at a much earlier age than previously reported, five-month-old infants already have hundreds of hours of visual experience. What, if any, visual experience is necessary for the construction or maintenance of category-selective regions? Would purely visual exposure to faces, places, and bodies be sufficient to evoke category selective responses ${ }^{49}$ ? Or must infants experience faces paired with social interaction, bodies paired with goal directed actions, and places paired with self-motion through the environment? Second, are the representations extracted and computations conducted in these regions similar to those of adults, or do these regions undergo major functional change between infancy and adulthood, and if so, what experience is necessary to produce that change? Research into these questions will ultimately provide scientific answers to the long-standing philosophical question of the origins of the human mind. 
A Infant fMRI Methods
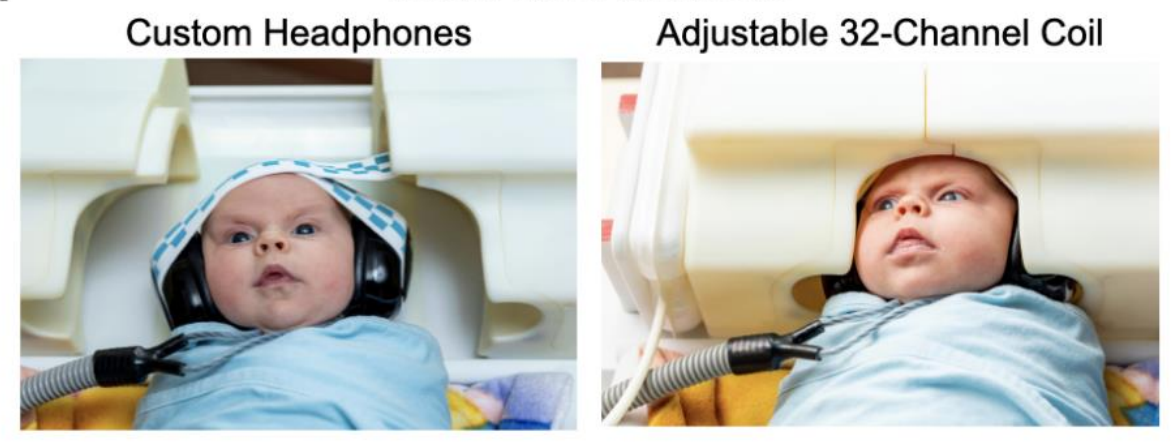

B

Dynamic Stimuli
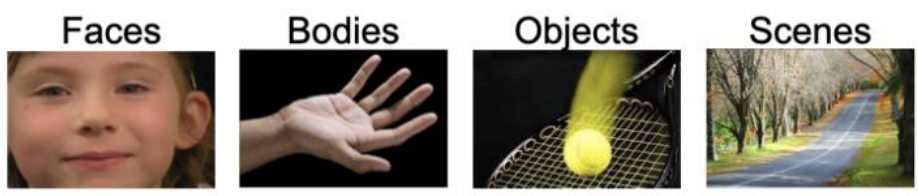

Baseline
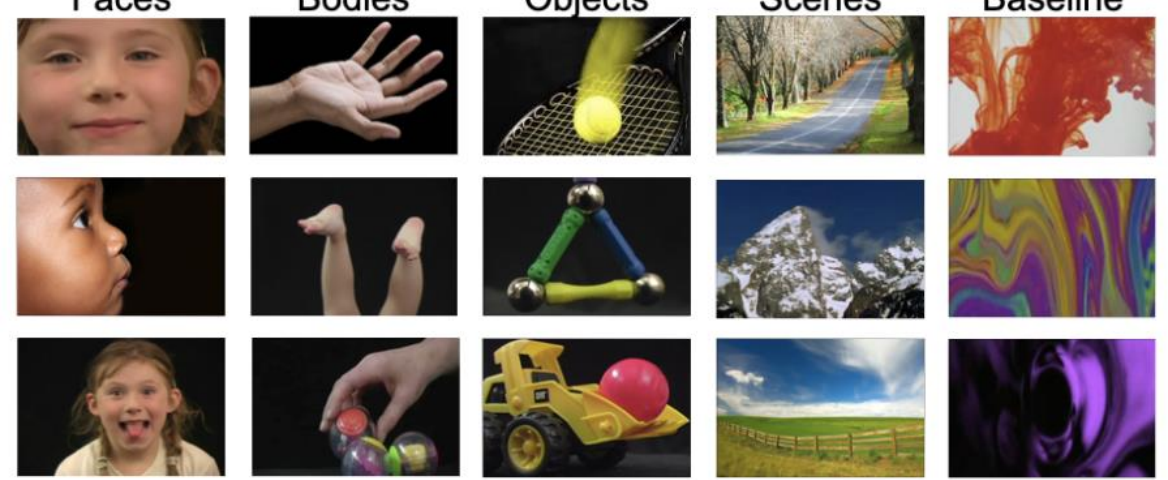

Figure 1. Infant scanning procedures and stimuli. a) Infants were swaddled, wore custom

MR-safe headphones to protect their hearing, and scanned in a newly designed 32-channel head coil (Coil 202124) that was shaped like a cradle and had adjustable frontal coils. b) Examples of face, body, object, scene, and baseline stimuli. Videos were $2.7 \mathrm{~s}$ long. To enhance infant attention, each video was followed by a $300 \mathrm{~ms}$ presentation of a still image from the same condition. Stimuli were displayed on a mirror over the infants' eyes and played continuously while the infant was awake, content, and attending. 


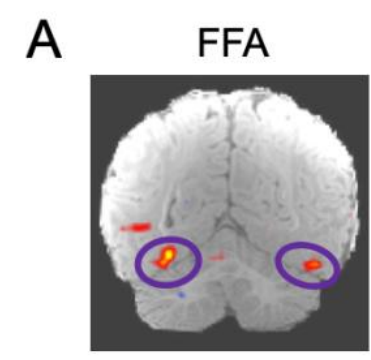

2.8 months

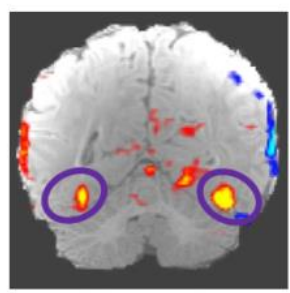

4.4 months

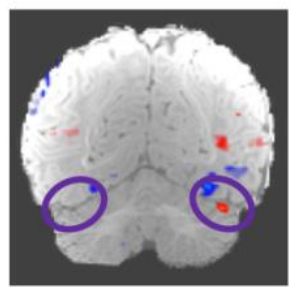

4.5 months

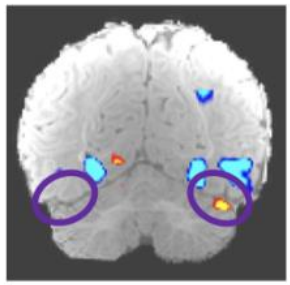

Group RFX ( $n=23)$
B

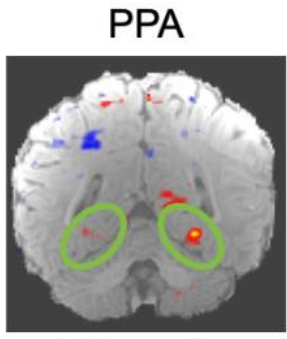

7.7 months

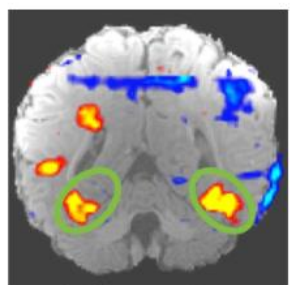

5.5 months

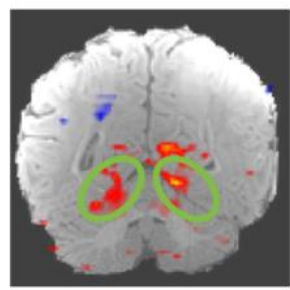

4.3 months

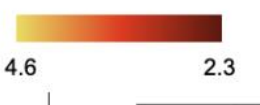

Z
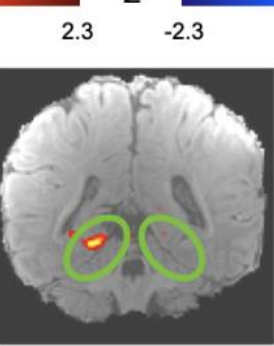

Group RFX ( $n=23)$

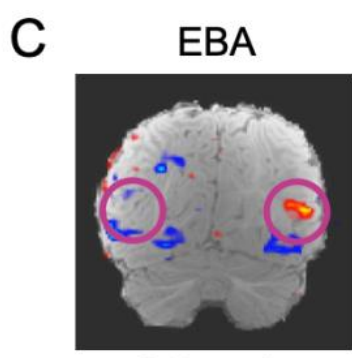

9.5 months

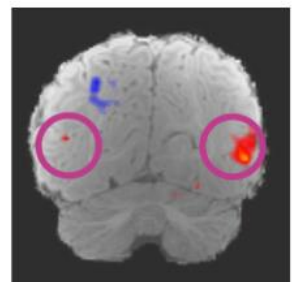

4.6 months

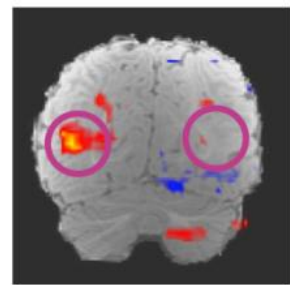

6.7 months

\section{Figure 2. Stereotyped location of category responses in the infant brain. Representative}

individual subject statistical maps (rows 1-3, threshold $P<0.01$ transformed to $\mathrm{Z}$ for visualization) and group random effects analyses $(\mathrm{n}=23$, bottom row, threshold $-\log (P)=2.0)$ revealed higher responses to faces>objects in the fusiform gyrus (a, location of adult FFA outlined in purple), to scenes>objects in the parahippocampal gyrus (b, location of adult PPA outlined in green), and to bodies>objects in lateral-occipital cortex (c, location of adult EBA outlined in pink). Individual and group maps displayed on representative infant anatomical image collected on the same coil (left hemisphere shown on the left and right on right). See Fig. S1 for multiple slices through each region from the group maps. 

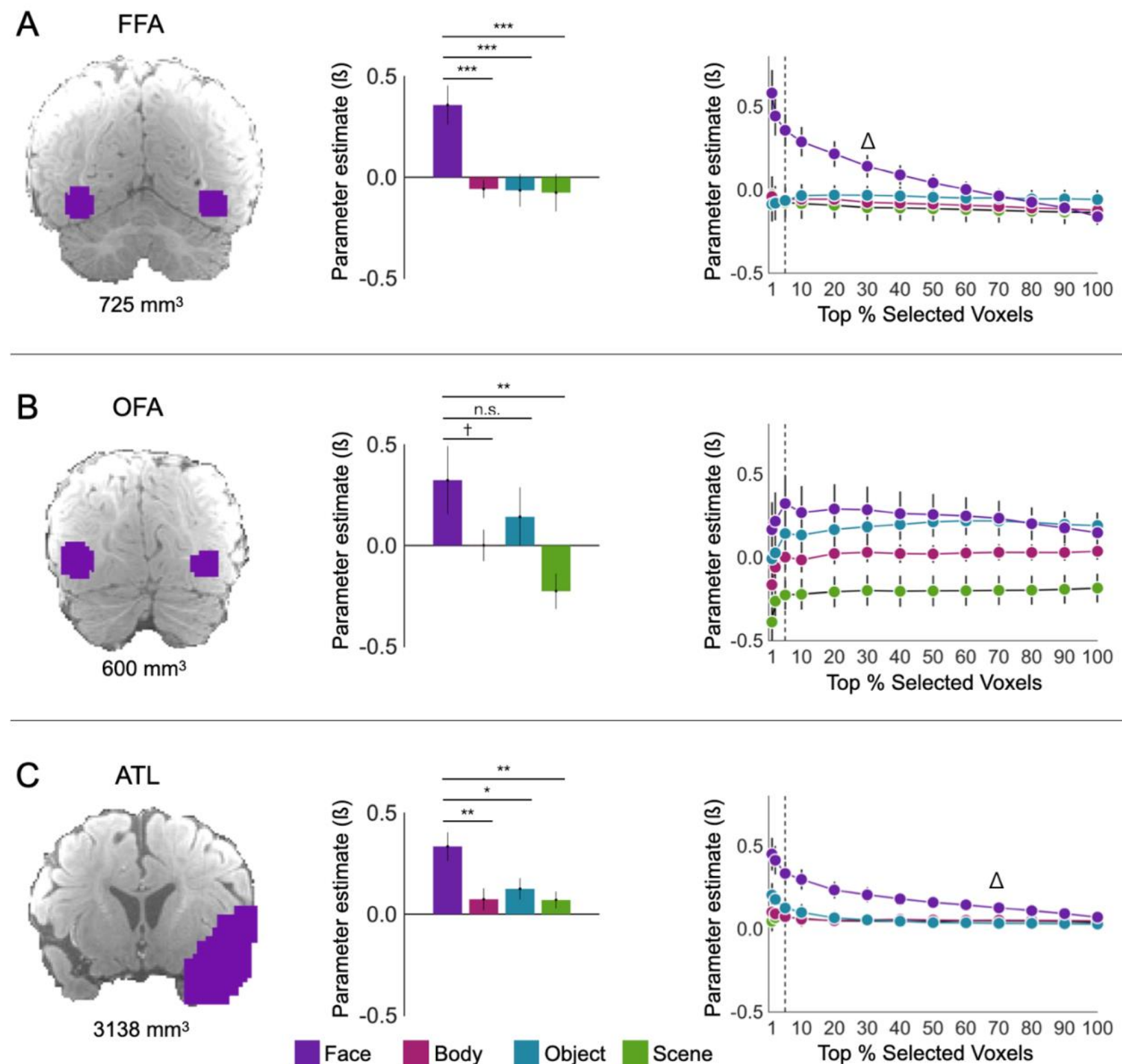

Face

Object Scene

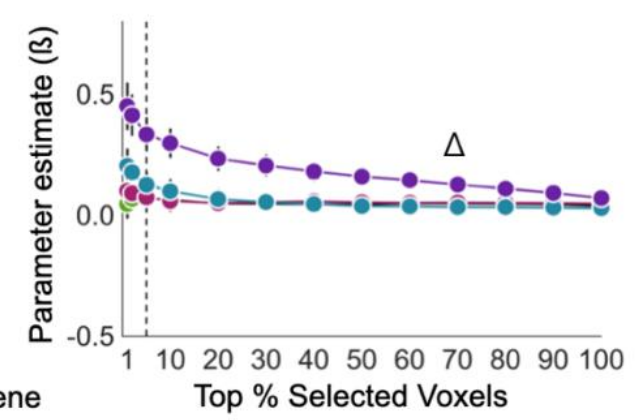

Figure 3. Face-selectivity in the infant brain. An fROI analysis $(n=20)$ with Coil 2021 data was conducted with adult-constrained parcels of the FFA ${ }^{25}, \mathrm{OFA}^{25}$, and $\mathrm{ATL}^{33}$ that were uniformly enlarged. All parcels are displayed on an anatomical image of an infant brain with face parcels shaded purple. Bar charts show the average response across participants in each fROI to each stimulus category (compared to baseline) in data independent of that used to define the fROI. Error bars are standard error of the mean accounting for within-subject variability ${ }^{50}$. Symbols used to report one-tailed statistics from linear mixed effect models: ${ }^{\dagger} P<0.1,{ }^{*} P<0.05$, ${ }^{* *} P<0.01,{ }^{* * *} P<0.001$. Statistics reported in Table S1. Line graphs show selectivity analysis with different proportions of voxels selected with the average response in independent data for faces plotted in purple, bodies plotted in pink, objects plotted in teal, and scenes plotted in green. The vertical dashed line marks the top 5\% and corresponds to the bar charts. The highest proportion of voxels with face-selective responses is indicated with a black triangle. Error bars are standard error of the mean. See Fig. S3 and Table S2 for comparison of Coil 2011 and Coil 2021 datasets. 
A PPA
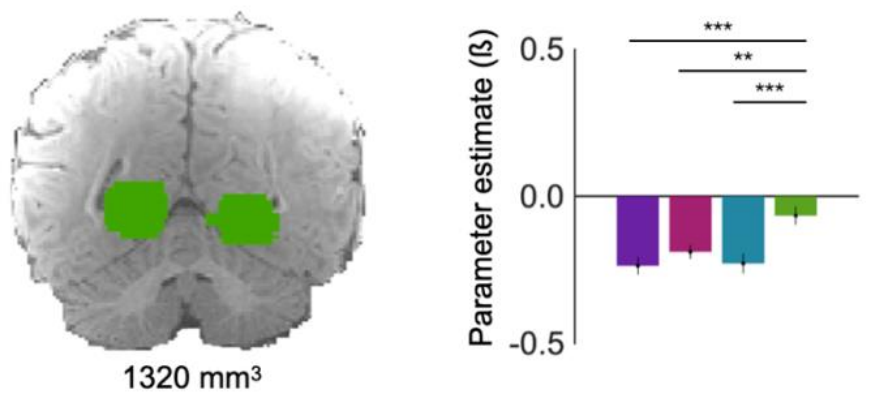

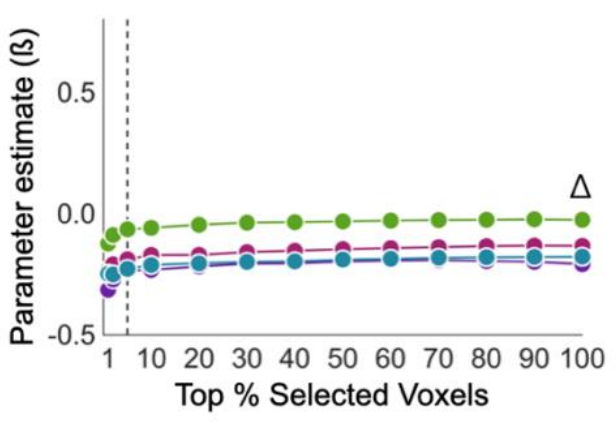

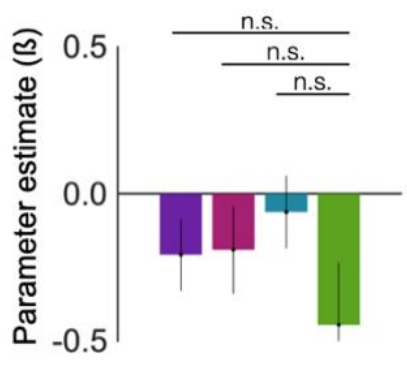

$420 \mathrm{~mm}^{3}$

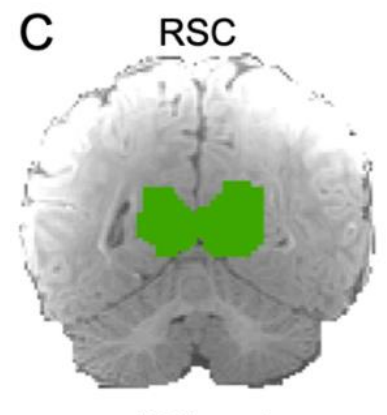

$1601 \mathrm{~mm}^{3}$

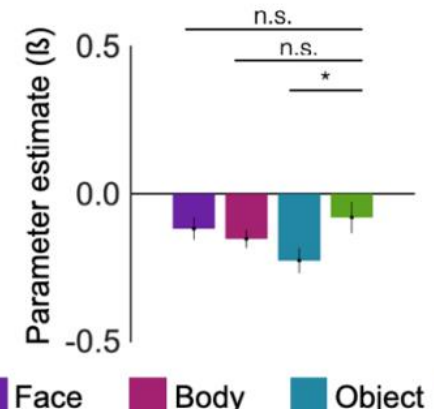

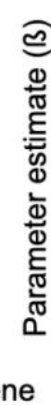

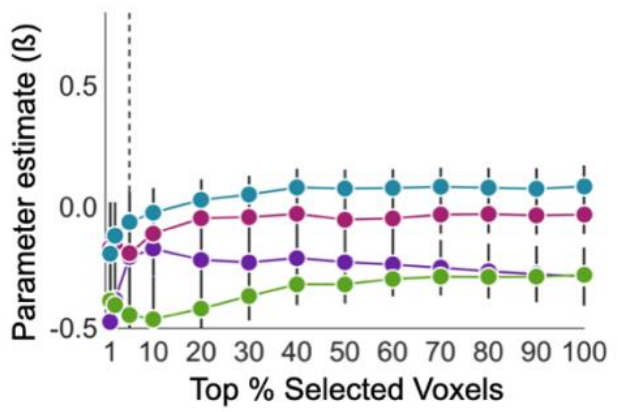

Figure 4. Scene-selectivity in the infant brain. An fROI analysis $(n=20)$ with Coil 2021 data was conducted with adult-constrained parcels of the $\mathrm{PPA}^{25}, \mathrm{OPA}^{25}$, and $\mathrm{RSC}^{25}$ that were uniformly enlarged. All parcels are displayed on an anatomical image of an infant brain with scene parcels shaded green. Bar charts show the average response across participants in each fROI to each stimulus category (compared to baseline) in data independent of that used to define the fROI. Error bars are standard error of the mean accounting for within-subject variability ${ }^{50}$. Symbols used to report one-tailed statistics from linear mixed effect models: ${ }^{\dagger} P<0.1,{ }^{*} P<0.05$, ${ }^{* *} P<0.01,{ }^{* * *} P<0.001$. Statistics reported in Table S1. Line graphs show selectivity analysis with different proportions of voxels selected with the average response in independent data for faces plotted in purple, bodies plotted in pink, objects plotted in teal, and scenes plotted in green. The vertical dashed line marks the top 5\% and corresponds to the bar charts. The highest proportion of voxels with scene-selective responses is indicated with a black triangle. Error bars are standard error of the mean. See Fig. S3 and Table S2 for comparison of Coil 2011 and Coil 2021 datasets. 
A $\quad E B A$

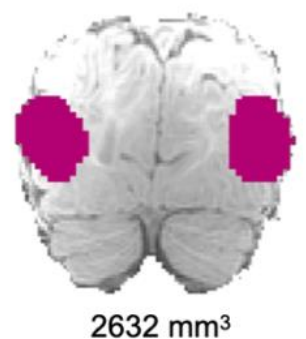

$2632 \mathrm{~mm}^{3}$
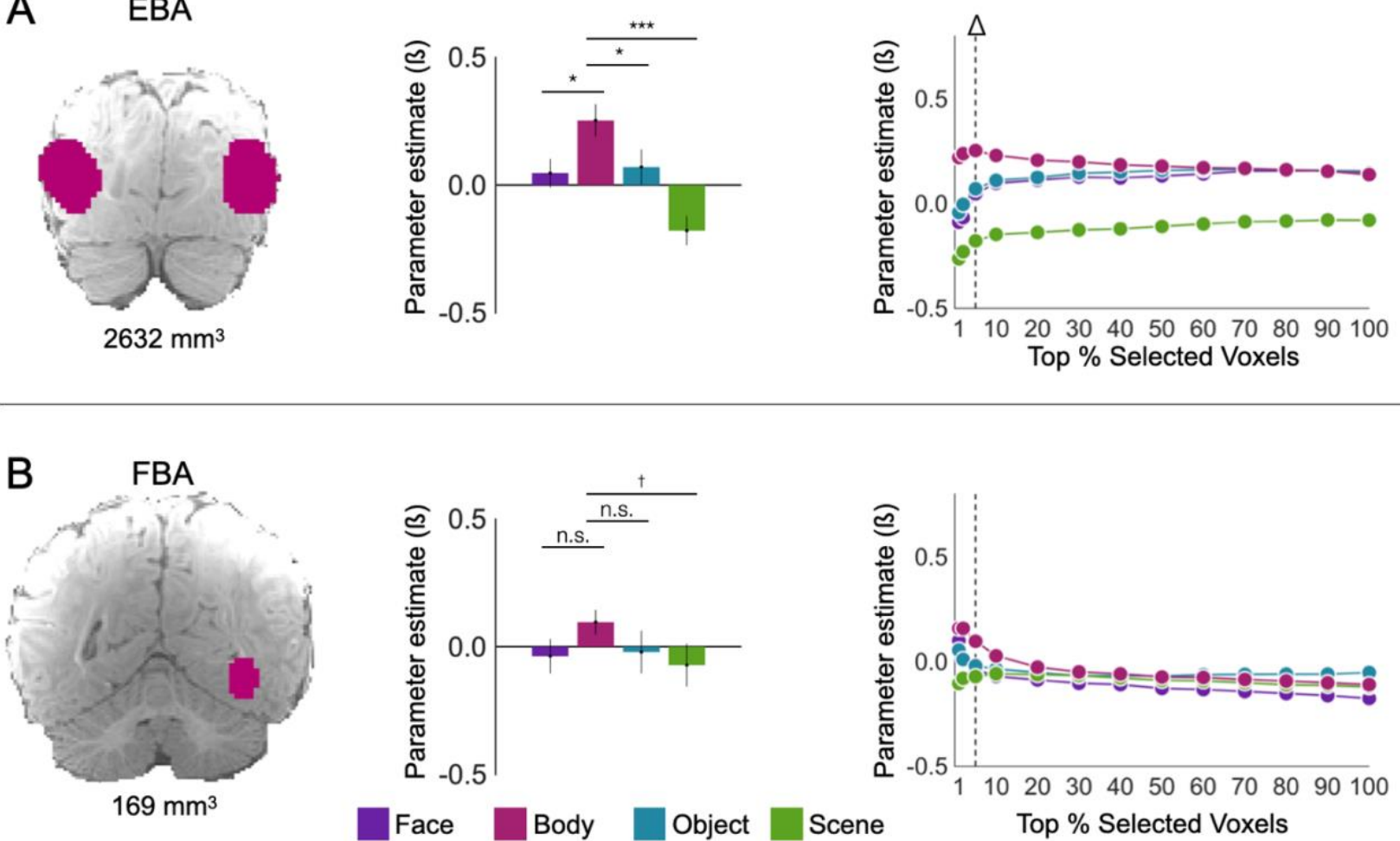

Figure 5. Body-selectivity in the infant brain. An fROI analysis $(n=20)$ with Coil 2021 data was conducted with adult-constrained parcels of the $\mathrm{FBA}^{25}$ and $\mathrm{EBA}^{25}$ that were uniformly enlarged. All parcels are displayed on an anatomical image of an infant brain with body parcels shaded pink. Bar charts show the average response across participants in each fROI to each stimulus category (compared to baseline) in data independent of that used to define the fROI. Error bars are standard error of the mean accounting for within-subject variability ${ }^{50}$. Symbols used to report one-tailed statistics from linear mixed effect models: ${ }^{\dagger} P<0.1,{ }^{*} P<0.05,{ }^{* *} P<0.01$, ${ }^{* * *} P<0.001$. Statistics reported in Table S1. Line graphs show selectivity analysis with different proportions of voxels selected with the average response in independent data for faces plotted in purple, bodies plotted in pink, objects plotted in teal, and scenes plotted in green. The vertical dashed line marks the top 5\% and corresponds to the bar charts. The highest proportion of voxels with body-selective responses is indicated with a black triangle. Error bars are standard error of the mean. See Fig. S3 and Table S2 for comparison of Coil 2011 and Coil 2021 datasets. 
371
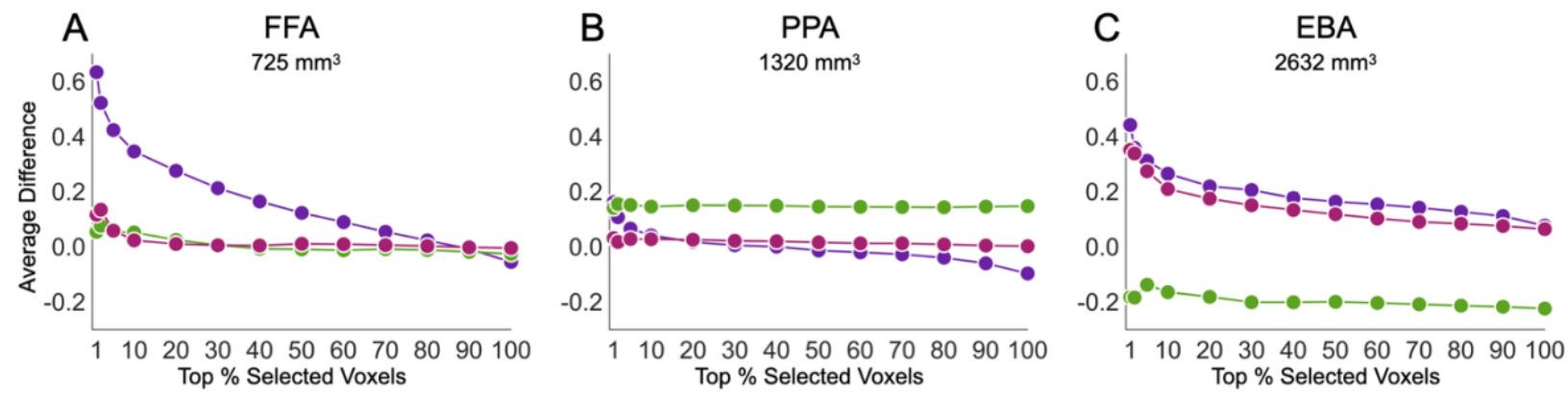

-Face Index

- Scene Index

-Body Index

Figure 6. Predicted selectivities are the highest in predicted regions. The top n\% of voxels for three contrasts (faces>objects, scenes>objects, bodies>objects) were selected in the FFA (a), PPA (b), and EBA (c) parcels. Responses were measured in held-out data. Face index: Facesmean(Bodies, Scenes, Objects); Scene Index:

Scenes-mean(Faces, Bodies, Objects); Body Index: Bodies-mean(Faces, Scenes, Objects). a) In the FFA parcel, voxels selected by the faces>objects contrast, up to the top $30 \%$ of the parcel, had a significant face-index in held out data. No other contrast identified significant category preferences at any threshold. b) In the PPA parcel, voxels selected by the scenes>objects contrast had a significant scene-index in held out data. No other contrast identified significant category preferences at any threshold. c) In the EBA parcel, voxels selected by bodies>objects had a significant body-index, and voxels selected by faces > objects had a significant face-index. Error bars are standard error of the mean. 
384 Acknowledgments: This research was carried out at the Athinoula A. Martinos

385 Imaging Center at the McGovern Institute for Brain Research at MIT. The authors thank Lyneé

386 Herrera for help collecting the Coil 2011 dataset and Isabel Nichoson for help collecting the Coil

3872021 dataset as well as Nayanika Das, Isabel Nichoson, and Somaia Saba for help with

388 registrations. We also that Steven Shannon, members of Saxe Lab, and members of the

389 Kanwisher Lab for help during recruitment and data collection; Stefano Anzellotti, Dana

390 Boebinger, Tyler Bonnen, Katharina Dobs, Anna Ivanova, Frederik Kamps, Owen Kunhardt, and

391 Somaia Saba for helpful comments on the manuscript; Kirsten Lydic for code and statistics

392 transposition review; Hannah A. LeBlanc for everything; and all the infants and their families.

393 Funding: We gratefully acknowledge support of this project by a National Science Foundation

394 (graduate fellowship to HLK; Collaborative Research Award \#1829470 to MAC), NIH

395 (\#1F99NS124175 to HLK; \#R21-HD090346-02 to RS; \#DP1HD091947 to NK); shared

396 instrumentation grant S10OD021569 for the MRI scanner), the McGovern Institute for Brain

397 Research at MIT, and the Center for Brains, Minds and Machines (CBMM), funded by an NSF

398 STC award (CCF-1231216).

400 Author contributions: HLK and RS designed the study. HLK collected the data. AT and BK

401 provided technical support in the development of the coil and sequence parameters. HLK

402 analyzed the data with input from and supervision by MAC, NK, and RS. HLK, MAC, NK, and

403 RS wrote the manuscript. All authors provided feedback on the final version.

404

405 Declaration of Interests: Nancy Kanwisher served on the advisory board of Current Biology. 


\section{STAR METHODS}

\section{RESOURCE AVAILABILITY}

\section{Lead contact}

- Further information and requests for resources should be directed to and will be fulfilled by the lead contact, Heather L. Kosakowski (heatherlkosakowski@gmail.com).

\section{Materials availability}

- This study did not generate new unique reagents.

\section{Data and code availability}

- De-identified results from the functional region of interest analyses have been deposited at osf.io and are publicly available as of the date of publication. Accession numbers are listed in the key resources table.

- Group maps for the three published contrasts have been deposited at osf.io and are publicly available as of the data of publication. Accession numbers are listed in the key resources table.

- All original code has been deposited at osf.io and is publicly available as of the date of publication. DOIs are listed in the key resources table.

- Any additional information required to reanalyze the data reported in this paper is available from the lead contact upon request.

\section{EXPERIMENTAL MODEL AND SUBJECT DETAILS}

Infants were recruited from the Boston metro area through word-of-mouth, fliers, and social media. Parents of participants were provided parking or, when travel was a constraint for participation, reimbursed travel expenses. Participants received a \$50 Amazon gift card for each visit and, whenever possible, printed images of their brain. We recruited 87 infants (2.1-11.9 months; mean age $=5.0$ months; 48 female) that participated in a total of 162 visits (the scanner was booked for two hours for each visit). Forty-two of these infants (2.1-9.7 months, mean=5.5 months, 21 female) were scanned on the Coil $2021^{24}$ and we recovered usable data (see data selection) from 26 infants (2.1-9.7 months, 11 female). The other 47 of these infants (2.5-11.9 months, mean $=4.5$ months, 26 female) were scanned on the Coil $2011^{51}$ and we recovered usable data from 26 infants (2.5-8.7 months, mean=4.8 months, 12 female). (For full subject, data, and inclusion details, see Table S3). We were unable to collect data from 15 subjects (included in the full count) due to technical error or lack of subject compliance. One subject (included in the full count) was excluded due to experimenter error. Infants were scanned with Coil 2011 until Coil 2021 was available. We stopped all data collection due to the COVID-19 pandemic. Ethical approval for this research was obtained through the Internal Review Board at MIT.

\section{METHOD DETAILS}

Stimuli. Infants watched blocks of videos and still images from five categories (faces, objects, bodies, scenes, curvy baseline; Fig. 1b). There are four important ways this paradigm is different than what was used previously ${ }^{17}$. First, all infants saw videos from all four conditions. Second, we selected a subset of videos that would make each block more visually and categorically homogenous within blocks and heterogenous across blocks (see below for a description). Third, 
each block included continuous videos that were $2.7 \mathrm{~s}$ and interleaved with still images from the same category (but not drawn from the videos) presented for $300 \mathrm{~ms}$. We added interleaved $300 \mathrm{~ms}$ still images with the hopes of 1) increasing the BOLD response by mitigating effects of adaptation and 2) increasing infant attention. One previous study indicated that $300 \mathrm{~ms}$ still image presentations led to the greatest neural response using $\mathrm{EEG}^{52}$, thus we chose a $300 \mathrm{~ms}$ still image presentation for our stimuli. We additionally wanted to maximize looking duration to each video so we shortened the $3 \mathrm{~s}$ videos from previous research ${ }^{17,53}$ to $2.7 \mathrm{~s}$. Finally, the baseline condition in previous research ${ }^{17}$ was scrambled blocks of scenes whereas in this study the baseline consists of curvy abstract scenes. Scrambled objects and scenes are a good control for a variety of low-level features of the object and scene blocks but not the face blocks. Thus, we chose to use curvy abstract scenes rather than scrambled objects or scrambled scenes to control for curvilinear visual features (see below for visual features of stimuli). As such, if the face condition is substantially greater than baseline, we can have some confidence that the response to faces is not merely due to curvilinear features.

All blocks were 18s and included 6 videos and 6 images. Face videos featured a single face of a child on a black background. Body stimuli focused on hands and feet of children wearing shorts, t-shirts, jeans, or dresses, with or without socks and shoes. Object blocks displayed toys (e.g., magnetic toys, plastic cars and planes, balls) on a black background, and scene blocks mountain or pastoral scenes. Baseline blocks were also $18 \mathrm{~s}$ and consisted of six $2.7 \mathrm{~s}$ videos and six still images that featured abstract color scenes such as liquid bubbles or tie-dyed patterns. Video and image order were randomized within blocks and block order was pseudorandom by category. There were 3 face blocks (frontal, averted, expressive), 2 body blocks, 3 object blocks, 3 scene blocks, and 1 block depicting hand-object interactions (not included in analysis).

The first 31 infants of the Coil 2011 dataset ( 8 of whom were included in the Coil 2011 fROI analysis) viewed face, body, object, scene, and abstract curvy videos. Video blocks were $18 \mathrm{~s}$ long, each video was $3 \mathrm{~s}$ long, and was no still image presentation. The videos played continuously for the full time the infant was in the scanner, awake, and attending. Additionally, instead of 12 condition blocks, there were 10 condition blocks - 3 face blocks, 3 scene blocks, 2 body blocks, and 2 object blocks - and the blocks played in a random order. Though the contents of each block was slightly different than the main paradigm, the videos were from the same stimulus $\operatorname{set}^{53}$.

A run began as soon as the infant was in the scanner and videos played continuously for as long as the infant was content, paying attention, and awake. All stimuli available on OSF (osf.io).

Data Collection. Infants were swaddled if possible. A parent or researcher went into the scanner with the infant while a second adult "scanner buddy" stood outside the bore of the scanner. The scanner buddy monitored infant attention and the TRs in which the infant was not looking at the stimuli were recorded for exclusion during preprocessing. Infants heard lullabies (https://store.jammyjams.net/products/pop-goes-lullaby-10) played through custom infant headphones for the duration of the scan.

Custom Head Coils. Forty-two infants were scanned in a newly designed 32-channel coil (Coil 2021) designed to comfortably cradle infants and wore custom infant MR-safe headphones ${ }^{24}$ 
(Fig. 1a). Infant headphones attenuated scanner noises (attenuation statistics reported in ${ }^{24}$ ) and allowed infants to listen to music at a comfortable volume for the duration of the scan. An adjustable coil design increased infant comfort, accommodated headphones, and suited a variety of infant head sizes (Fig. 1a). Coil 2021 and infant headphones were designed for a Siemens Prisma 3T scanner and enabled the use of an EPI with standard trajectory with 44 near-axial $160 \mathrm{~mm}$, matrix $=80 \times 80$, slice thickness $=2 \mathrm{~mm}$, slice gap $=0 \mathrm{~mm}$ ). A few subjects were scanned on a different EPI with standard trajectory with near-axial slices (repetition time, $\mathrm{TR}=$ $3 \mathrm{~s}$, echo time, $\mathrm{TE}=30 \mathrm{~ms}$, flip angle $=90^{\circ}$, field of view, $\mathrm{FOV}=208 \mathrm{~mm}$, matrix $=104 \times 104$, slice thickness $=2 \mathrm{~mm}$, slice gap $=0 \mathrm{~mm}$ ). Four of these subjects were included in the fROI analysis.

Data from 47 infants were collected with Coil 2011 with the same data collection methods reported by Deen et $\mathrm{al}^{17}$. We used a custom 32-channel infant coil designed for a Siemens Trio 3T scanner ${ }^{51}$ (Coil 2011) and a quiet EPI with sinusoidal trajectory ${ }^{54}$ with 22 near-axial slices (repetition time, $\mathrm{TR}=3 \mathrm{~s}$, echo time, $\mathrm{TE}=43 \mathrm{~ms}$, flip angle $=90^{\circ}$, field of view, $\mathrm{FOV}=192 \mathrm{~mm}$, matrix $=64 \times 64$, slice thickness $=3 \mathrm{~mm}$, slice gap $=0.6 \mathrm{~mm}$ ). The sinusoidal acquisition sequence caused substantial distortions in the functional images (Fig. S3b).

Data Selection (subrun creation): To be included in the analysis, data had to meet the criteria for low head motion that was reported by Deen et al ${ }^{17}$. Data were cleaved between consecutive timepoints having more than 2 degrees or $2 \mathrm{~mm}$ of motion, creating "subruns," which contained at least 24 consecutive low-motion volumes. All volumes included in a subrun were extracted from the original "run" data (a "run" began when the subject went into the scanner and ended when the subject fell asleep or was fussy) and combined to create a new Nifti file for each subrun. Paradigm files were similarly updated for each subrun. Volumes with greater than 0.5 degrees or mm of motion between volumes were scrubbed. We used highly conservative motion thresholds ${ }^{23}$ that were identical to the thresholds we used previously ${ }^{17}$, to ensure inclusion of only the highest quality data in our analysis. If a subject had more than one dataset (data collected within a 30-day window were analyzed as a single dataset), we included only the dataset with more volumes that met our criteria for inclusion. One subject had two datasets but the dataset with more volumes was missing a large portion the temporal lobe due to motion. For this subject we used the dataset with fewer volumes but an intact temporal lobe. This procedure resulted in 514.3 minutes of useable data (mean=5.9 minutes, s.d.=11.3) from the Coil 2021 dataset and 566.00 minutes of useable data (mean=6.5 minutes, s.d.=12.6) from the Coil 2011 dataset.

To be included in the group random effects analysis, subjects had to have at least 96 volumes that met the above motion threshold criteria. We only included subjects from each dataset that were collected with the same acquisition sequence. This resulted in 23 subjects from the Coil 2021 dataset (2.1-9.7 months, mean=5.7 months) and 29 subjects from the Coil 2011 dataset (2.5-8.8 months, mean $=4.8$ months) met these criteria.

To be included in the fROI analysis, subjects had to have at least two subruns with at least 96 volumes in each subrun (one to choose voxels showing the relevant contrast, and the other to independently extract response magnitudes from the selected voxels). This resulted in a final 
fROI dataset of 20 datasets (3.0-9.7 months; mean=5.8 months) for the Coil 2021 dataset (16 with the standard acquisition sequence and 3 with a different acquisition sequence and 1 with both sequences) and 19 datasets (18 unique subjects) for the Coil 2011 dataset (2.5-8.8 months, mean=4.8 months). Due to the variable amount of data in each subrun for each subject and the impact this could have on reliable parameter estimates from the GLM, we first combined or split subruns to approximately equate the amount of data across subruns within subjects. For example, if a subject had three subruns and the first was 35 volumes, the second was 57 volumes and third was 220 volumes, then we concatenated the first two subruns to create one subrun and we split the third subrun into 2 resulting in a total of three subruns with approximately 100 volumes per subrun.

Preprocessing. Each subrun was processed individually. First, an individual functional image was extracted from the middle of the subrun to be used for registering the subruns to one another for further analysis. Then, each subrun was motion corrected using FSL MCFLIRT. If more than 3 consecutive images had more than $0.5 \mathrm{~mm}$ or 0.5 degrees of motion, there had to be at least 7 consecutive low-motion volumes following the last high-motion volume in order for those volumes to be included in the analysis. Additionally, each subrun had to have at least 24 volumes after accounting for motion and sleep TRs. Functional data were skull-stripped (FSL BET2), intensity normalized, and spatially smoothed with a 3mm FWHM Gaussian kernel (FSL SUSAN).

Data registration. Due to the substantial distortion in these data and the lack of an anatomical image from many subjects, we registered all functional data to a representative functional image collected with the same coil and acquisition parameters (referred to as the functional template image). As there is no standard approach to the use of common space in infant MRI research ${ }^{55}$, we elected to use a template image collected with the same acquisition parameters as each subject. For Coil 2011 data, the functional template image was the same image used by Deen and colleagues ${ }^{17}$. For Coil 2021 data, we selected a representative functional image from a representative subject for whom we also had a high-quality anatomical image. All subruns were registered within subjects to a target image from that subject. Then each subject target image was registered to a template functional image collected using the same coil and acquisition parameters. First, the middle image of each subrun was extracted and used as an example image for registration. If the middle image was corrupted by motion or distortion, a better image was selected to be the example image. The example image from the middle subrun of the first visit was used as the target image and all other subruns from that subject were registered to that subject's target image. The target image for each subject was registered to a template image collected using the same acquisition parameters. Subrun and target image registrations were concatenated so that each subrun was individually registered to template space. We attempted to register each image using a rigid, an affine, and a partial affine registration with FSL FLIRT. The best image was selected by eye from the three registration options and manually tuned with the Freesurfer GUI for the best possible data alignment. To display group results, images were transformed to the anatomical space of the template image.

Parcels / Search Spaces. Group constrained parcels were acquired from previous adult research to localize areas of selectivity ${ }^{25,33}$. Face-selective parcels included OFA, FFA, and ATL. Sceneselective parcels included OPA, PPA, and RSC. Body-selective parcels included EBA and FBA. 
After transforming the FFA parcel to individual subject space, we noticed that the peak face activation in the fusiform gyrus often fell just anterior to the FFA parcel. We attributed this difference to difficulties in obtaining reliable registrations with infant functional data and used the -dilM function in fslmaths to uniformly increase the size of all parcels. As this was an unplanned change in our analysis, we also report fROI results from the original parcels (Table S1) and the dilated parcels (Figs. 3-5; Table S1). The large ventral and lateral parcels are the same ones we used in Deen et al ${ }^{17}$ and results are reported in Figure S3c and Table S2. All parcels will be available on OSF upon publication.

\section{QUANTIFICATION AND STATISTICAL ANALYSIS}

Subject-level Beta and Contrast Maps. Functional data were analyzed with a whole brain voxel-wise general linear model (GLM) using custom MATLAB scripts. The GLM included 4 condition regressors (faces, bodies, objects, and scenes), 6 motion regressors, a linear trend regressor, and 5 PCA noise regressors. Condition regressors were defined as a boxcar function for the duration of the stimulus presentation (18s blocks). Infant inattention or sleep was accounted for using a single impulse nuisance ('sleep') regressor. The sleep regressor was defined as a boxcar function with a 1 for each TR the infant was not looking at the stimuli, and the corresponding TR was set to 0 for all condition regressors. Boxcar condition and sleep regressors were convolved with an infant hemodynamic response function (HRF) that is characterized by a longer time to peak and deeper undershoot compared to the standard adult HRF $^{56}$. PCA noise regressors were computed using a method similar to GLMDenoise ${ }^{57}$, defined in ${ }^{17}$. Data and regressors were demeaned for each subrun. Next, demeaned data and regressors were concatenated across subruns, run regressors were added to account for differences between runs, and beta values were computed for each condition in a whole-brain voxel-wise GLM. Three subject-level contrast maps were computed as the difference between the condition of interest beta (i.e., face beta, body beta, or scene beta) and the object beta for each voxel using inhouse MATLAB code. Results from subject-level contrast maps are reported in Fig. 2.

Group Random Effects Analyses. To test whether there was systematic overlap between areas of activation, we conducted group random effects analyses for eligible data. For visualization and reporting purposes subject-level voxelwise statistical maps were transformed to coil-specific functional template space (see data registration method above) and group random effects analyses were performed using Freesurfer mri_concat and Freesurfer mri_glmfit. Each group map was then transformed to coilspecific anatomical space. We did not combine data across coils due to difficulty registering the two different image types. Results from group random effects analyses are reported in Fig. 2 and Fig. S1.

Functional Region of Interest. To constrain search areas for voxel selection, we used anatomically defined parcels (see parcels/search spaces) transformed to subject native space. We used an iterative leave-one-subrun-out procedure such that data were concatenated across all subruns except one prior to the whole-brain voxel-wise GLM and contrasts were computed (described above). The top 5\% of voxels with the greatest difference between the category of interest (i.e., faces, bodies, or scenes) and objects within an anatomical constraint parcel were selected as the fROI for that subject, and the parameter estimates were extracted from a GLM on the left-out subrun. Beta values were averaged across folds within a participant and weighted 
betas were averaged across participants. The use of top 5\% and weighted betas was an analytic decision based on previous research ${ }^{17}$. The strength of selecting the top 5\% of voxels is that we equally sample all subjects for a representation of the overall pattern of response across subjects. Thus, it is possible to find a response that is unreliable and even has the reverse preference in left out data (see OPA in Fig. 4b as an example - voxels were selected that had a greater response to scenes compared to objects but in independent data, the response to objects was greater than the response to scenes, indicating that across infants, there was not a reliable scene response in

Category-Selectivity. To determine whether a region's response was category-selective, we fit the beta-values using a linear mixed effects model. In each region, we had an a priori hypothesis about which of the four conditions would elicit the largest response. So, in each model, we dummy-coded the other three control conditions, to test the hypotheses that the response to each control condition was lower than to the predicted preferred condition. For example, for regions predicted to be face-selective, we fit a model in MATLAB with the expression:

fitlme (data f1+f2+f3+age+sex+motion+(1|subject)

where the three dummy-coded condition regressors are f1 (bodies), f2 (objects) and f 3 (scenes). Fixed effects parameters of no interest were age, motion, and sex. Motion was the fraction of scrubbed volumes. Subject was coded as a random intercept for all models. In the Coil 2011 analyses, we also included a fixed effect paradigm parameter ("para") because two slightly different versions of the experimental paradigm were used during data collection.

The response in a parcel was deemed selective if the fixed effect coefficient for each of the three control conditions was significantly negative, using a t-test. Because predictions are unidirectional, reported p-values are one-tailed. For example, a face parcel was only deemed face-selective if the parameter estimates for the body, object, and scene regressors were significantly negative. Results for the fROI analyses are reported in Figs. 3-5, Fig. S3, and Tables S1-S2.

Models of stimulus visual statistics. Each frame was extracted from each video. Frames and still images were converted to grayscale and normalized. To obtain spatial frequency information, we computed a Fourier transform on each image. Low- and high-spatial frequency were extracted from each frame of each stimulus using the methods and cut-offs described by 58 and averaged across all images within a category. Each category value was then normalized relative to the baseline value. Nasr and colleagues ${ }^{27}$ found that scene and object stimuli are characterized by the presence of angles and that the presence of straight lines and right angles drive activation in the PPA. Similarly, Yue and colleagues ${ }^{28,29}$ found that face stimuli are characterized by the presence of curves and activate areas along the fusiform gyrus. Thus, we also extracted curvilinear information using code provided by ${ }^{27}$ and methods described by ${ }^{28,29}$. Briefly, each normalized grayscale image from a block (e.g., each face block was computed separately) was reduced to $140 \times 210$ pixels and averaged together. For rectilinear information, angled Gabor filters $\left(90^{\circ}\right.$ and $\left.180^{\circ}\right)$ with four different spatial frequencies $(1,2,4$, and 8$)$ were applied to each pixel to assess the amount of angular content. Rectilinear values were averaged across pixels and blocks. Curvilinear values were computed in a similar manner except each angled Gabor filter $\left(30^{\circ}, 60^{\circ}, 90^{\circ}, 120^{\circ}, 150^{\circ}\right.$, and $\left.180^{\circ}\right)$ had five different curve depths. 
681 Curvilinear values for each frame from each block were averaged together. All visual statistics 682 results for this analysis are reported in Fig. S2.

683

684 


\section{REFERENCES}

1. Kanwisher N. Functional specificity in the human brain: A window into the functional architecture of the mind. Proc Natl Acad Sci. 2010;107(25):11163-70.

2. Kanwisher N, McDermott J, Chun MM. The Fusiform Face Area: A Module in Human Extrastriate Cortex Specialized for Face Perception. J Neurosci. 1997;17(11):4302-11.

3. Epstein R, Kanwisher N. A cortical representation the local visual environment. Nature. 1998;392(6676):598-601.

4. Downing PE, Jiang Y, Shuman M, Kanwisher N. A cortical area selective for visual processing of the human body. Science (80- ). 2001;293(September):2470-3.

5. Grill-Spector K, Golarai G, Gabrieli J. Developmental neuroimaging of the human ventral visual cortex. Trends Cogn Sci. 2008;12(4):152-62.

6. Golarai G, Liberman A, Grill-Spector K. Experience Shapes the Development of Neural Substrates of Face Processing in Human Ventral Temporal Cortex. Cereb Cortex. 2015;(27):1229-44.

7. Golarai G, Ghahremani DG, Whitfield-Gabrieli S, Reiss A, Eberhardt JL, Gabrieli JDE, et al. Differential development of high-level visual cortex correlates with category-specific recognition memory. Nat Neurosci. 2007;10(4):512-22.

8. Meissner TW, Nordt M, Weigelt S. Prolonged functional development of the parahippocampal place area and occipital place area. Neuroimage. 2019;191(February):104-15.

9. Cohen MA, Dilks DD, Koldewyn K, Weigelt S, Feather J, Kell AJ, et al. Representational similarity precedes category selectivity in the developing ventral visual pathway. Neuroimage. 2019 Aug 15;197:565-74.

10. Peelen M V., Glaser B, Vuilleumier P, Eliez S. Differential development of selectivity for faces and bodies in the fusiform gyrus. Dev Sci. 2009;12(6):16-25.

11. Kamps FS, Hendrix CL, Brennan PA, Dilks DD. Connectivity at the origins of domain specificity in the cortical face and place networks. Proc Natl Acad Sci U S A. 2020;117(11):6163-9.

12. de Heering A, Rossion B. Rapid categorization of natural face images in the infant right hemisphere. Elife. 2015;4(JUNE):1-14.

13. Kobayashi M, Otsuka Y, Kanazawa S, Yamaguchi MK, Kakigi R. The processing of faces across non-rigid facial transformation develops at 7 month of age: A fNIRS-adaptation study. BMC Neurosci. 2014;15(1):1-8.

14. Powell LJ, Deen B, Saxe R. Using individual functional channels of interest to study cortical development with fNIRS. Dev Sci. 2018;21(4):e12595.

15. Meltzoff AN, Ramírez RR, Saby JN, Larson E, Taulu S, Marshall PJ. Infant brain responses to felt and observed touch of hands and feet: an MEG study. Dev Sci. 2018;21(5):1-13.

16. Lisboa IC, Queirós S, Miguel H, Sampaio A, Santos JA, Pereira AF. Infants' cortical processing of biological motion configuration - A fNIRS study. Infant Behav Dev. 2020;

17. Deen B, Richardson H, Dilks DD, Takahashi A, Keil B, Wald LL, et al. Organization of high-level visual cortex in human infants. Nat Commun. 2017;8(13995):1-10.

18. Livingstone MS, Vincent JL, Arcaro MJ, Srihasam K, Schade PF, Savage T. Development of the macaque face-patch system. Nat Commun. 2017;8:1-12. 
19. Powell LJ, Kosakowski HL, Saxe R. Social Origins of Cortical Face Areas. Trends Cogn Sci. 2018;22(9):752-63.

20. Arcaro MJ, Livingstone MS. On the relationship between maps and domains in inferotemporal cortex. Nat Rev Neurosci. 2021;

21. Arcaro MJ, Schade PF, Livingstone MS. Universal Mechanisms and the Development of the Face Network: What You See Is What You Get. Annu Rev Vis Sci. 2019;5(1).

22. Arcaro MJ, Livingstone MS. A hierarchical, retinotopic proto-organization of the primate visual system at birth. Elife. 2017;6:1-24.

23. Ellis CT, Skalaban LJ, Yates TS, Bejjanki VR, Córdova NI, Turk-Browne NB. How to read a baby's mind: Re-imagining fMRI for awake, behaving infants. Nat Commun. 2020;

24. Ghotra A, Kosakowski HL, Takahashi A, Etzel R, May MW, Scholz A, et al. A sizeadaptive 32-channel array coil for awake infant neuroimaging at 3 Tesla MRI. Magn Reson Med. 2021;86(3):1773-85.

25. Julian JB, Fedorenko E, Webster J, Kanwisher N. An algorithmic method for functionally defining regions of interest in the ventral visual pathway. Neuroimage. 2012;

26. Hasson U, Levy I, Behrmann M, Hendler T, Malach R. Eccentricity bias as an organizing principle for human high-order object areas. Neuron. 2002;34(3):479-90.

27. Nasr S, Echavarria CE, Tootell RBH. Thinking Outside the Box: Rectilinear Shapes Selectively Activate Scene-Selective Cortex. J Neurosci. 2014;34(20):6721-35.

28. Yue X, Pourladian IS, Tootell RBH, Ungerleider LG. Curvature-processing network in macaque visual cortex. Proc Natl Acad Sci U S A. 2014;111(33).

29. Yue X, Robert S, Ungerleider LG. Curvature processing in human visual cortical areas. Neuroimage. 2020;222(August).

30. Livingstone MS, Arcaro MJ, Schade PF. Cortex Is Cortex: Ubiquitous Principles Drive Face-Domain Development. Physiol Behav. 2016;176(1):139-48.

31. Pitcher D, Walsh V, Duchaine B. The role of the occipital face area in the cortical face perception network. Exp Brain Res. 2011;209(4):481-93.

32. Kamps FS, Julian JB, Kubilius J, Kanwisher N, Dilks DD. The occipital place area represents the local elements of scenes. Neuroimage. 2016;132:417-24.

33. Kriegeskorte N, Formisano E, Sorger B, Goebel R. Individual faces elicit distinct response patterns in human anterior temporal cortex. Proc Natl Acad Sci U S A. 2007;104(51):20600-5.

34. Bratch A, Engel S, Burton P, Kersten D. The Fusiform Body Area Represents Spatial Relationships Between Pairs of Body Parts. J Vis. 2018;

35. Van Grootel TJ, Meeson A, Munk MHJ, Kourtzi Z, Movshon JA, Logothetis NK, et al. Development of visual cortical function in infant macaques: A BOLD fMRI study. PLoS One. 2017;12(11):1-30.

36. Tsantani M, Kriegeskorte N, Storrs K, Williams AL, McGettigan C, Garrido L. FFA and OFA encode distinct types of face identity information. J Neurosci. 2021 Jan 15;JN-RM1449-20.

37. Henriksson L, Mur M, Kriegeskorte N. Faciotopy-A face-feature map with face-like topology in the human occipital face area. Cortex. 2015;72:156-67.

38. Henriksson L, Mur M, Kriegeskorte N. Rapid Invariant Encoding of Scene Layout in Human OPA. Neuron. 2019;103(1):161-171.e3. 
39. Taylor JC, Wiggett AJ, Downing PE. Functional MRI analysis of body and body part representations in the extrastriate and fusiform body areas. J Neurophysiol. 2007;98(3):1626-33.

40. Brandman T, Yovel G. Bodies are Represented as Wholes Rather Than Their Sum of Parts in the Occipital-Temporal Cortex. Cereb Cortex. 2016;26(2):530-43.

41. Pitcher D, Ianni G, Ungerleider LG. A functional dissociation of face-, body- and sceneselective brain areas based on their response to moving and static stimuli. Sci Rep. 2019;9(1):1-9.

42. Pitcher D, Ungerleider LG. Evidence for a Third Visual Pathway Specialized for Social Perception. Trends Cogn Sci. 2020;

43. Ewbank MP, Lawson RP, Henson RN, Rowe JB, Passamonti L, Calder AJ. Changes in "top-down" connectivity underlie repetition suppression in the ventral visual pathway. $\mathrm{J}$ Neurosci. 2011;31(15):5635-42.

44. Cabral L, Zubiaurre L, Wild C, Linke A, Cusack R. Category-Selective Visual Regions Have Distinctive Signatures of Connectivity in Early Infancy. BioRxiv. 2019;

45. Saygin ZM, Osher DE, Norton ES, Youssoufian DA, Beach SD, Feather J, et al. Connectivity precedes function in the development of the visual word form area. Nat Neurosci. 2016;19(9):1250-5.

46. Li J, Osher DE, Hansen HA, Saygin ZM. Innate connectivity patterns drive the development of the visual word form area. Sci Rep. 2020;10(1):1-12.

47. Murty NAR, Teng S, Beeler D, Mynick A, Oliva A, Kanwisher NG. Visual Experience is not Necessary for the Development of Face Selectivity in the Lateral Fusiform Gyrus. bioRxiv. 2020;

48. van den Hurk J, Van Baelen M, Op de Beeck HP. Development of visual category selectivity in ventral visual cortex does not require visual experience. Proc Natl Acad Sci. 2017;114(22):E4501-10.

49. Dobs K, Martinez J, Kell AJE, Kanwisher N. Brain-like functional specialization emerges spontaneously in deep neural networks. 2021;1-30.

50. Cousineau D. Confidence intervals in within-subject designs: A simpler solution to Loftus and Masson's method. Tutor Quant Methods Psychol. 2005;1(1):42-5.

51. Keil B, Alagappan V, Mareyam A, McNab JA, Fujimoto K, Tountcheva V, et al. Sizeoptimized 32-channel brain arrays for 3 T pediatric imaging. Magn Reson Med. 2011 Dec 1;66(6):1777-87.

52. Kouider S, Stahlhut C, Gelskov S V., Barbosa LS, Dutat M, de Gardelle V, et al. A Neural Marker of Perceptual Consciousness in Infants. Science (80- ). 2013;340(6130):376-80.

53. Pitcher D, Dilks DD, Saxe RR, Triantafyllou C, Kanwisher N. Differential selectivity for dynamic versus static information in face-selective cortical regions. Neuroimage. 2011;56(4):2356-63.

54. Zapp J, Schmitter S, Schad LR. Sinusoidal echo-planar imaging with parallel acquisition technique for reduced acoustic noise in auditory fMRI. J Magn Reson Imaging. 2012;36(3):581-8.

55. Dufford AJ, Hahn CA, Peterson H, Gini S, Mehta S, Alfano A, et al. (Un)common space in infant neuroimaging studies: a systematic review of infant templated. bioRvix. 2021;1:1-30.

56. Arichi T, Fagiolo G, Varela M, Melendez-Calderon A, Allievi A, Merchant N, et al. 
820 Development of BOLD signal hemodynamic responses in the human brain. Neuroimage. $821 \quad 2012 ; 63(2): 663-73$.

822 57. Kay KN, Rokem A, Winawer J, Dougherty RF, Wandell BA. GLMdenoise: A fast, 823 automated technique for denoising task-based fMRI data. Front Neurosci. 2013;7(7 824 DEC):1-15.

825 58. Rajimehr R, Devaney KJ, Bilenko NY, Young JC, Tootell RBH. The "parahippocampal place area" responds preferentially to high spatial frequencies in humans and monkeys. 


\section{Supplemental Information}

Selective responses to faces, scenes, and bodies

in the ventral visual pathway of infants

Heather L. Kosakowski, Michael A. Cohen, Atsushi Takahashi, Boris Keil, Nancy Kanwisher, and Rebecca Saxe 
$\mathrm{L}$

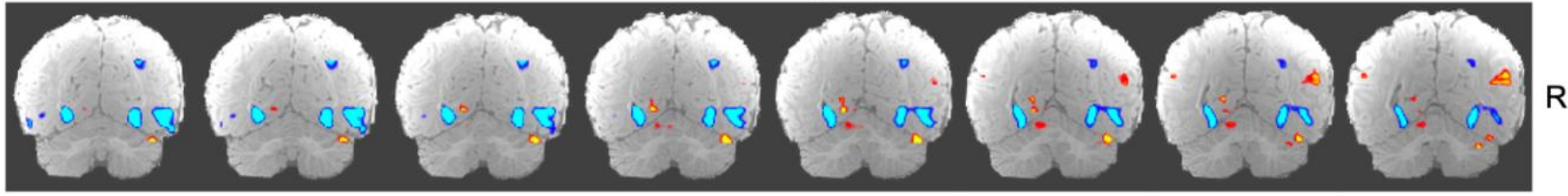

Scenes > Objects

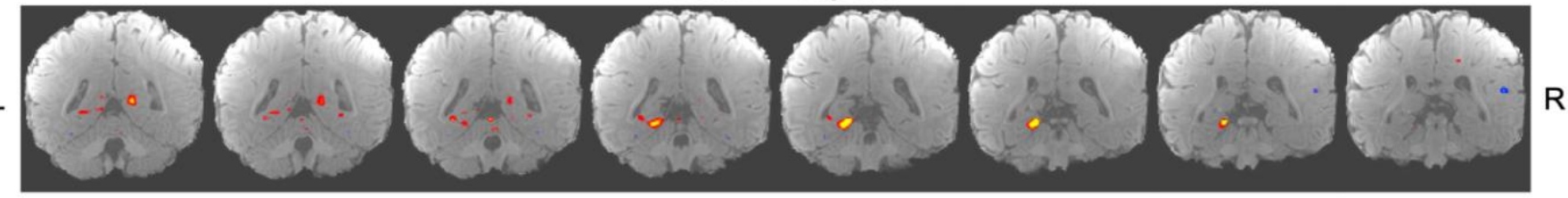

Bodies > Objects

$\mathrm{L}$

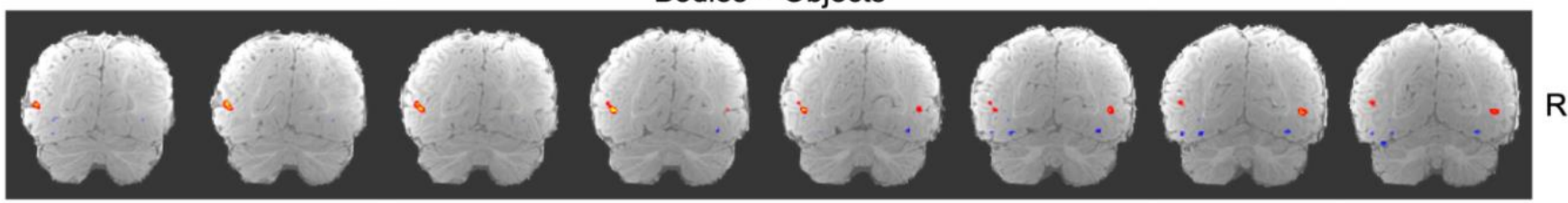

Posterior

Anterior

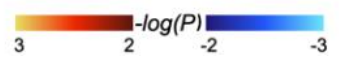

Figure S1. Face, scene, and body patches in infant cortex, Related to Figure 2. Multiple slices from group random effects analyses showing face and scene patches in ventral temporal cortex and body patch and lateral occipital cortex. 

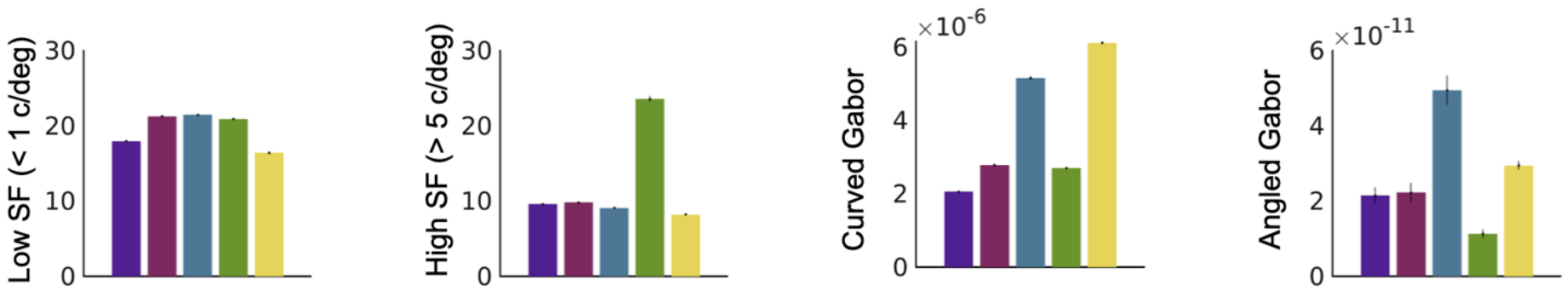

Face

Body

Object

Scene

Baseline

Figure S2. Visual statistics, Related to STAR Methods. Low- and high-spatial frequency were extracted from each frame of each stimulus using the methods and cut-offs described by ${ }^{51}$ and averaged across frames within a category. Rectilinear and curvilinear content was estimated for each block using code provided on Open Science Framework (OSF) by ${ }^{\mathrm{S} 2}$ and methods described by $33, \mathrm{S4}$. All category values for each visual feature were averaged across conditions blocks with faces in purple, bodies in pink, objects in teal, scenes in green, and baseline in yellow. 


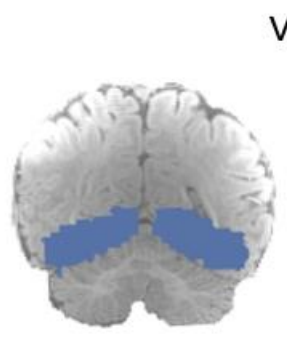

Ventral

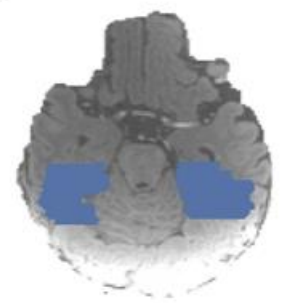

Lateral
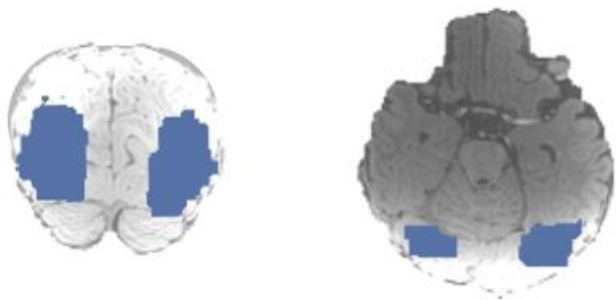

Anatomical Search Space

B

Coil 2011

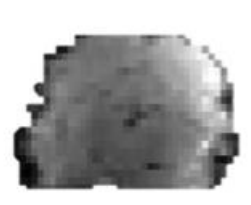

Coronal

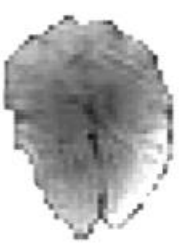

Axial

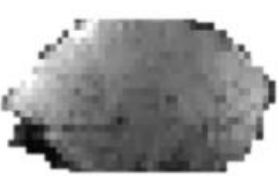

Sagital

Example Functional Images

Coil 2021

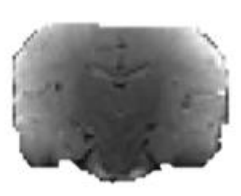

Coronal

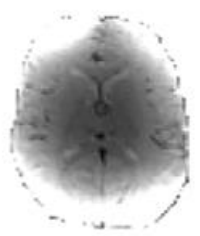

Axial

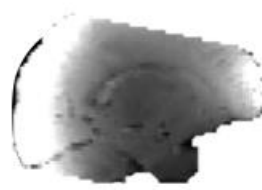

Sagital

C

Selectivity Differences in Coil 2011 and Coil 2021 Datasets

Ventral Face Selectivity
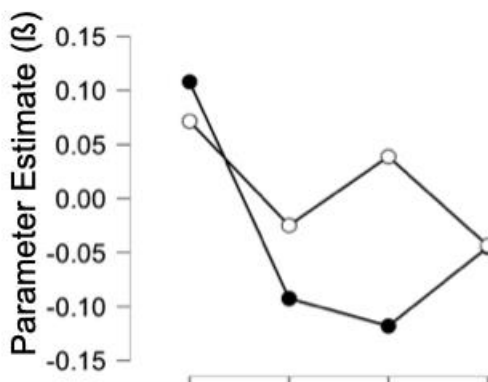

Face Body Object Scene
Ventral Scene Selectivity

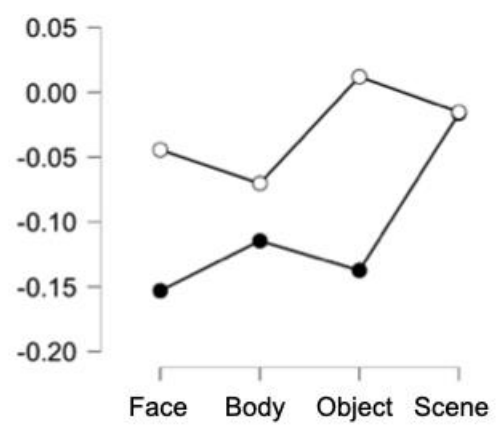

Lateral Body Selectivity

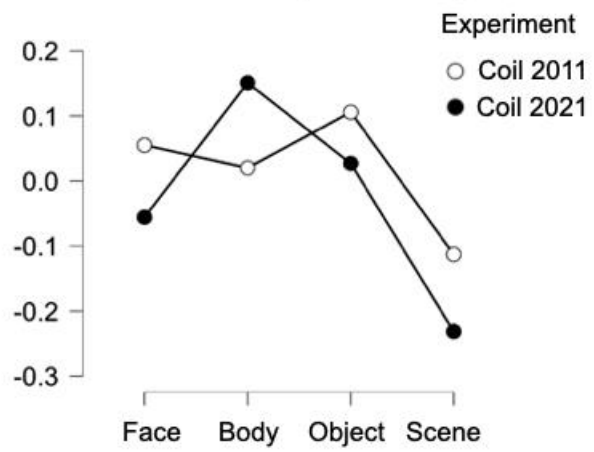

D Coil 2011 and Coil 2021 Datasets are Matched on Data Quantity, Motion \& Subject Age
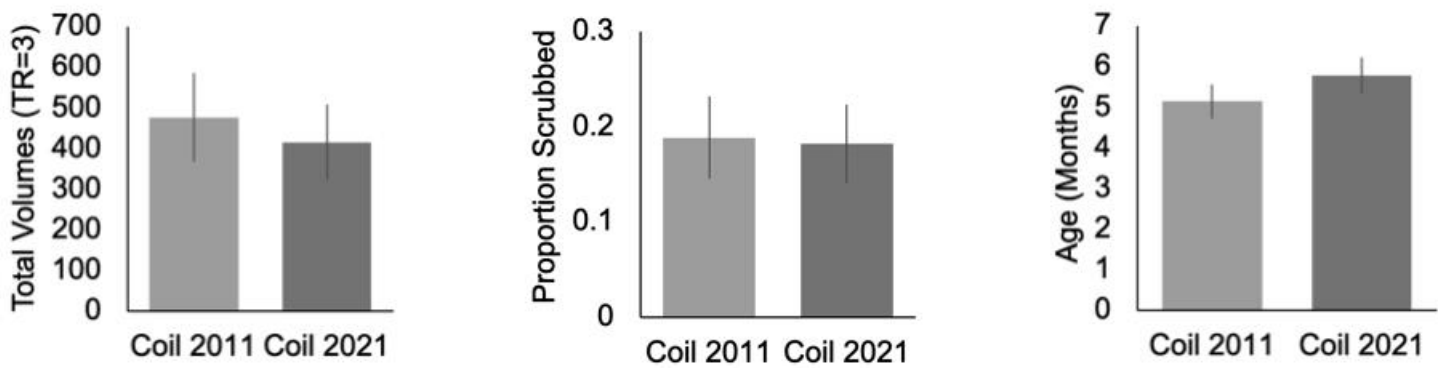

Figure S3. Comparison between Coil 2011 and Coil 2021 datasets, Related to Figures 3-5 and STAR Methods. Why did we find clear category selective responses in the present study (significantly higher responses in FFA, PPA, and EBA to their preferred stimuli than to each of the other 3 conditions), whereas the earlier Deen et al. study ${ }^{55}$ did not? The two studies differed in coil, acquisition sequence (EPI), paradigm, analysis methods (including the use of different anatomical constraint parcels), and number of subjects. To determine which of these factors may have made the 
difference, we analyzed a dataset that had more subjects ( $\mathrm{n}=19$ datasets from 18 infants) but used the same coil and acquisition sequence as Deen et al. This "Coil 2011" dataset did not overlap with the data reported in either Deen et al. or with the main ("Coil 2021") data reported in the present paper. (a) Anatomically-constrained parcels (ventral and lateral) from Deen et al. ${ }^{55}$ were used for an $\mathrm{fROI}$ analysis displayed on anatomical image. (b) Distortions in infant fMRI data: representative image of $\mathrm{FMRI}$ data collected with Coil $2011^{\mathrm{S6}}$ using an EPI with a sinusoidal trajectory ${ }^{\mathrm{S7}}$ (left) and representative image of $\mathrm{fMRI}$ data collected with Coil $2021^{\mathrm{S} 8}$ using a standard, higher resolution EPI. (c) The Coil $2021(\mathrm{~N}=19)$ dataset was more selective than the Coil $2011(\mathrm{~N}=19)$ dataset with a significant experiment (Coil 2011 vs Coil 2021) by fROI by condition interaction $(F(6,108)=2.39$, $\eta^{2}=0.013, P<0.03$ ). (d) The Coil 2011 and Coil 2021 datasets are matched on age (Coil 2011 2.5-8.5, mean=5.1, s.d.=1.8; Coil 2021 2.98-9.7, mean=5.8, s.d.=2.0), motion (Coil 2011 0.06-0.48, mean=0.18, s.d. $=0.11$; Coil $20210.00-0.41$, mean $=0.18$, s.d. $=0.12$ ), and average volumes per subject (Coil 2011 212-1077, mean=477, s.d.=225; Coil 2021 108-1006, mean=416, s.d.=213). Motion plotted as a proportion of scrubbed volumes and age plotted in months. Error bars represent standard error of the mean. 


\begin{tabular}{|c|c|c|c|c|c|c|c|c|}
\hline Faces > Objects & Int. & Age & Sex & Mot. & $\mathrm{n} / \mathrm{a}$ & F-B & $\mathrm{F}-\mathrm{O}$ & F-S \\
\hline OFA (0) & $\begin{array}{c}0.49 \\
(-0.06-1.04)\end{array}$ & $\begin{array}{c}0.22 \\
(-0.13-0.56)\end{array}$ & $\begin{array}{c}0.06 \\
(-0.61-0.74)\end{array}$ & $\begin{array}{c}0.11 \\
(-0.23-0.46)\end{array}$ & $\mathrm{n} / \mathrm{a}$ & $\begin{array}{c}-0.38 \\
(-0.86-0.10)\end{array}$ & $\begin{array}{c}-0.12 \\
(-0.61-0.36)\end{array}$ & $\begin{array}{c}-0.62 \\
(-1.11--0.14)\end{array}$ \\
\hline FFA (o) & $\begin{array}{c}0.33 \\
(0.05-0.61)\end{array}$ & $\begin{array}{c}0.12 \\
(-0.04-0.29)\end{array}$ & $\begin{array}{c}0.07 \\
(-0.25-0.39)\end{array}$ & $\begin{array}{c}-0.20 \\
(-0.36--0.03)\end{array}$ & $\mathrm{n} / \mathrm{a}$ & $\begin{array}{c}-0.37 \\
(-0.66--0.09)\end{array}$ & $\begin{array}{c}-0.34 \\
(-0.62--0.05)\end{array}$ & $\begin{array}{c}-0.51 \\
(-0.79--0.22)\end{array}$ \\
\hline ATL (o) & $\begin{array}{c}0.28 \\
(0.09-0.47)\end{array}$ & $\begin{array}{c}0.01 \\
(-0.11-0.13)\end{array}$ & $\begin{array}{c}0.08 \\
(-0.16-0.31)\end{array}$ & $\begin{array}{c}0.09 \\
(-0.03-0.21)\end{array}$ & $n / a$ & $\begin{array}{c}-0.23 \\
(-0.40--0.06)\end{array}$ & $\begin{array}{c}-0.18 \\
(-0.35--0.01)\end{array}$ & $\begin{array}{c}-0.26 \\
(-0.43--0.09)\end{array}$ \\
\hline OFA (d) & $\begin{array}{c}0.45 \\
(0.05-0.84)\end{array}$ & $\begin{array}{c}0.13 \\
(-0.09-0.36)\end{array}$ & $\begin{array}{c}-0.26 \\
(-0.71-0.19)\end{array}$ & $\begin{array}{c}-0.16 \\
(-0.39-0.07)\end{array}$ & $\mathrm{n} / \mathrm{a}$ & $\begin{array}{c}-0.32 \\
(-0.72-0.07)\end{array}$ & $\begin{array}{c}-0.18 \\
(-0.58-0.22)\end{array}$ & $\begin{array}{c}-0.55 \\
(-0.95--0.15)\end{array}$ \\
\hline FFA (d) & $\begin{array}{c}0.34 \\
(0.05-0.62)\end{array}$ & $\begin{array}{c}0.16 \\
(-0.02-0.33)\end{array}$ & $\begin{array}{c}0.04 \\
(-0.30-0.39)\end{array}$ & $\begin{array}{c}-0.15 \\
(-0.33-0.02)\end{array}$ & $\mathrm{n} / \mathrm{a}$ & $\begin{array}{c}-0.42 \\
(-0.67--0.16)\end{array}$ & $\begin{array}{c}-0.42 \\
(-0.67--0.16)\end{array}$ & $\begin{array}{c}-0.43 \\
(-0.69--0.18)\end{array}$ \\
\hline ATL (d) & $\begin{array}{c}0.30 \\
(0.11-0.49)\end{array}$ & $\begin{array}{c}0.01 \\
(-0.12-0.11)\end{array}$ & $\begin{array}{c}0.07 \\
(-0.16-0.30)\end{array}$ & $\begin{array}{c}0.09 \\
(-0.03-0.20)\end{array}$ & $\mathrm{n} / \mathrm{a}$ & $\begin{array}{c}-0.26 \\
(-0.44--0.08)\end{array}$ & $\begin{array}{c}-0.21 \\
(-0.39--0.03)\end{array}$ & $\begin{array}{c}-0.26 \\
(-0.44--0.09)\end{array}$ \\
\hline Scenes > Objects & Int. & Age & Sex & Mot. & S-F & S-B & $\mathrm{S}-\mathrm{O}$ & $\mathrm{n} / \mathrm{a}$ \\
\hline OPA (o) & $\begin{array}{c}-0.52 \\
(-1.08-0.05)\end{array}$ & $\begin{array}{c}0.20 \\
(-0.10-0.50)\end{array}$ & $\begin{array}{c}-0.05 \\
(-0.65-0.55)\end{array}$ & $\begin{array}{c}-0.10 \\
(-0.41-0.20)\end{array}$ & $\begin{array}{c}0.04 \\
(-0.60-0.68)\end{array}$ & $\begin{array}{c}0.23 \\
(-0.41-0.87)\end{array}$ & $\begin{array}{c}0.54 \\
(-0.09-1.18)\end{array}$ & $\mathrm{n} / \mathrm{a}$ \\
\hline PPA (0) & $\begin{array}{c}-0.05 \\
(-0.19-0.10)\end{array}$ & $\begin{array}{c}-0.02 \\
(-0.11-0.08)\end{array}$ & $\begin{array}{c}-0.05 \\
(-0.23-0.14)\end{array}$ & $\begin{array}{c}-0.09 \\
(-0.19--0.00)\end{array}$ & $\begin{array}{c}-0.17 \\
(-0.29--0.05)\end{array}$ & $\begin{array}{c}-0.17 \\
(-0.29--0.04)\end{array}$ & $\begin{array}{c}-0.20 \\
(-0.32--0.08)\end{array}$ & $\mathrm{n} / \mathrm{a}$ \\
\hline RSC (o) & $\begin{array}{c}-0.09 \\
(-0.28-0.10)\end{array}$ & $\begin{array}{c}-0.03 \\
(-0.15-0.10)\end{array}$ & $\begin{array}{c}0.02 \\
(-0.22-0.27)\end{array}$ & $\begin{array}{c}0.11 \\
(-0.01-0.23)\end{array}$ & $\begin{array}{c}0.03 \\
(-0.11-0.17)\end{array}$ & $\begin{array}{c}-0.02 \\
(-0.17-0.12)\end{array}$ & $\begin{array}{c}-0.08 \\
(-0.23-0.06)\end{array}$ & $\mathrm{n} / \mathrm{a}$ \\
\hline OPA (d) & $\begin{array}{c}-0.39 \\
(-0.77--0.02)\end{array}$ & $\begin{array}{c}0.20 \\
(0.03-0.37)\end{array}$ & $\begin{array}{c}-0.10 \\
(-0.45-0.24)\end{array}$ & $\begin{array}{c}-0.14 \\
(-0.31-0.04)\end{array}$ & $\begin{array}{c}0.24 \\
(-0.24-0.71)\end{array}$ & $\begin{array}{c}0.26 \\
(-0.22-0.73)\end{array}$ & $\begin{array}{c}0.38 \\
(-0.09-0.86)\end{array}$ & $\mathrm{n} / \mathrm{a}$ \\
\hline PPA (d) & $\begin{array}{c}-0.07 \\
(-0.20-0.07)\end{array}$ & $\begin{array}{c}-0.01 \\
(-0.08-0.10)\end{array}$ & $\begin{array}{c}0.00 \\
(-0.17-0.18)\end{array}$ & $\begin{array}{c}-0.07 \\
(-0.16-0.02)\end{array}$ & $\begin{array}{c}-0.17 \\
(-0.27--0.07)\end{array}$ & $\begin{array}{c}-0.12 \\
(-0.22--0.03)\end{array}$ & $\begin{array}{c}-0.16 \\
(-0.26--0.07)\end{array}$ & $\mathrm{n} / \mathrm{a}$ \\
\hline $\mathrm{RSC}(\mathrm{d})$ & $\begin{array}{c}-0.11 \\
(-0.28-0.05) \\
\end{array}$ & $\begin{array}{c}-0.01 \\
(-0.12-0.10) \\
\end{array}$ & $\begin{array}{c}0.07 \\
(-0.14-0.28) \\
\end{array}$ & $\begin{array}{c}0.09 \\
(-0.02-0.20) \\
\end{array}$ & $\begin{array}{c}-0.04 \\
(-0.17-0.09) \\
\end{array}$ & $\begin{array}{c}-0.07 \\
(-0.21-0.06) \\
\end{array}$ & $\begin{array}{c}-0.15 \\
(-0.28--0.01) \\
\end{array}$ & $\mathrm{n} / \mathrm{a}$ \\
\hline Bodies > Objects & Int. & Age & Sex & Mot. & $B-F$ & $\mathrm{n} / \mathrm{a}$ & $\mathrm{B}-\mathrm{O}$ & $B-S$ \\
\hline EBA (o) & $\begin{array}{c}0.31 \\
(-0.04-0.67)\end{array}$ & $\begin{array}{c}0.07 \\
(-0.17-0.31)\end{array}$ & $\begin{array}{c}-0.04 \\
(-0.52-0.43)\end{array}$ & $\begin{array}{c}0.06 \\
(-0.18-0.31)\end{array}$ & $\begin{array}{c}-0.30 \\
(-0.55--0.04)\end{array}$ & $\mathrm{n} / \mathrm{a}$ & $\begin{array}{c}-0.18 \\
(-0.44-0.08)\end{array}$ & $\begin{array}{c}-0.50 \\
(-0.75--0.24)\end{array}$ \\
\hline FBA (o) & $\begin{array}{c}0.04 \\
(-0.19-0.28)\end{array}$ & $\begin{array}{c}0.05 \\
(-0.06-0.16)\end{array}$ & $\begin{array}{c}0.05 \\
(-0.27-0.16)\end{array}$ & $\begin{array}{c}-0.18 \\
(-0.29--0.07)\end{array}$ & $\begin{array}{c}-0.12 \\
(-0.41-0.18)\end{array}$ & $\mathrm{n} / \mathrm{a}$ & $\begin{array}{c}-0.15 \\
(-0.45-0.14)\end{array}$ & $\begin{array}{c}-0.12 \\
(-0.42-0.18)\end{array}$ \\
\hline EBA (d) & $\begin{array}{c}0.31 \\
(0.02-0.59) \\
\end{array}$ & $\begin{array}{c}0.05 \\
(-0.15-0.24)\end{array}$ & $\begin{array}{c}-0.11 \\
(-0.49-0.27)\end{array}$ & $\begin{array}{c}0.04 \\
(-0.15-0.24)\end{array}$ & $\begin{array}{c}-0.21 \\
(-0.40--0.01)\end{array}$ & $\mathrm{n} / \mathrm{a}$ & $\begin{array}{c}-0.18 \\
(-0.38-0.01)\end{array}$ & $\begin{array}{c}-0.43 \\
(-0.63--0.24)\end{array}$ \\
\hline FBA (d) & $\begin{array}{c}0.03 \\
(-0.16-0.22) \\
\end{array}$ & $\begin{array}{c}0.10 \\
(0.01-0.20)\end{array}$ & $\begin{array}{c}0.15 \\
(-0.04-0.33) \\
\end{array}$ & $\begin{array}{c}-0.15 \\
(-0.24--0.05) \\
\end{array}$ & $\begin{array}{c}-0.13 \\
(-0.36-0.10) \\
\end{array}$ & $\mathrm{n} / \mathrm{a}$ & $\begin{array}{c}-0.12 \\
(-0.35-0.11) \\
\end{array}$ & $\begin{array}{c}-0.17 \\
(-0.40-0.06) \\
\end{array}$ \\
\hline
\end{tabular}

₹ Parameter estimates from linear mixed-effects model with confidence interval in parenthesis; $\mathrm{P}<0.05$ indicated in bold; intercept (int) is the difference between baseline and the condition of interest; motion (mot.) is the proportion of scrubbed voxels.

\section{Table S1. Linear mixed-effects models in original (o) and dilated (d) parcels, Related to Figures 1-3 and STAR Methods.}




\begin{tabular}{|c|c|c|c|c|c|c|c|c|c|}
\hline Face & Int. & Age & Sex & Mot. & Para. & $\mathrm{n} / \mathrm{a}$ & F-B & $\mathrm{F}-\mathrm{O}$ & F-S \\
\hline \multirow[t]{2}{*}{ Coil 2011 Lateral } & -0 & & 0.16 & & -0.07 & $n / a$ & -0.08 & -0.02 & -0.11 \\
\hline & 0.15 & $(-0.05-0.08)$ & $(0.02-0.31)$ & $(-0.22--0.08)$ & $(-0.21-0.07)$ & & $(-0.20-0.04)$ & $(-0.14-0.11)$ & $(-0.23-0.01)$ \\
\hline \multirow[t]{2}{*}{ Coil 2011 Ventral } & 0.08 & 0.25 & 0.14 & -0.03 & -0.19 & $\mathrm{n} / \mathrm{a}$ & -0.10 & -0.03 & -0.12 \\
\hline & $(-0.14-0.30)$ & $(0.14-0.35)$ & $(-0.16-0.44)$ & $(-0.17-0.11)$ & $(-0.47-0.09)$ & & $(-0.25-0.06)$ & $(-0.19-0.12)$ & $(-0.27-0.04)$ \\
\hline \multirow[t]{2}{*}{ Coil 2021 Lateral } & 0.27 & 0.18 & -0.13 & -0.10 & $\mathrm{n} / \mathrm{a}$ & $\mathrm{n} / \mathrm{a}$ & -0.15 & -0.23 & -0.45 \\
\hline & $(-0.02-0.56)$ & $(0.01-0.36)$ & $(-0.47-0.22)$ & $(-0.28-0.07)$ & & & $(-0.43-0.12)$ & $(-0.51-0.04)$ & $(-0.73--0.18)$ \\
\hline \multirow[t]{2}{*}{ Coil 2021 Ventral } & 0.11 & 0.06 & 0.00 & -0.06 & $\mathrm{n} / \mathrm{a}$ & $\mathrm{n} / \mathrm{a}$ & -0.20 & -0.23 & -0.15 \\
\hline & $(0.02-0.19)$ & $(0.02-0.10)$ & $(-0.07-0.08)$ & $(-0.10--0.02)$ & & & \multicolumn{3}{|c|}{$(-0.31--0.09)(-0.34--0.12)(-0.26--0.04)$} \\
\hline Scenes > Objects & Int. & Age & Sex & Mot. & Para. & $\mathrm{S}-\mathrm{F}$ & S-B & $\mathrm{S}-\mathrm{O}$ & $\mathrm{n} / \mathrm{a}$ \\
\hline \multirow[t]{2}{*}{ Coil 2011 Lateral } & -0.03 & -0.01 & 0.07 & -0.15 & -0.14 & -0.09 & -0.05 & -0.02 & $\mathrm{n} / \mathrm{a}$ \\
\hline & $(-0.24-0.17)$ & $(-0.09-0.07)$ & $0.22-0.36)$ & $(-0.29--0.02)$ & $(-0.41-0.12)$ & $(-0.20-0.01)$ & $(-0.16-0.05)$ & $(-0.12-0.08)$ & \\
\hline \multirow[t]{2}{*}{ Coil 2011 Ventral } & -0.00 & 0.27 & 0.12 & -0.02 & -0.16 & -0.03 & -0.05 & 0.03 & $\mathrm{n} / \mathrm{a}$ \\
\hline & $(-0.23-0.23)$ & $(0.17-0.38)$ & $0.20-0.43)$ & $(-0.17-0.12)$ & $(-0.46-0.13)$ & $(-0.18-0.12)$ & $(-0.20-0.09)$ & $(-0.12-0.18)$ & \\
\hline \multirow[t]{2}{*}{ Coil 2021 Lateral } & -0.18 & 0.10 & -0.00 & 0.03 & $\mathrm{n} / \mathrm{a}$ & 0.17 & 0.19 & 0.20 & $\mathrm{n} / \mathrm{a}$ \\
\hline & $(-0.35--0.02)$ & $(0.01-0.19)$ & $(-0.17-0.18)$ & $(-0.06-0.11)$ & & $(-0.03-0.36)$ & $(-0.00-0.39)$ & $(0.01-0.40)$ & \\
\hline \multirow[t]{2}{*}{ Coil 2021 Ventral } & -0.03 & 0.03 & 0.03 & -0.04 & $\mathrm{n} / \mathrm{a}$ & -0.14 & -0.10 & -0.12 & $\mathrm{n} / \mathrm{a}$ \\
\hline & $(-0.12-0.05)$ & $(-0.03-0.08)$ & $(-0.07-0.14)$ & $(-0.09-0.01)$ & & \multicolumn{4}{|c|}{$(-0.22--0.06)(-0.18--0.02)(-0.20--0.04)$} \\
\hline Bodies > Objects & Int. & Age & Sex & Mot. & Para. & $\mathrm{B}-\mathrm{F}$ & $\mathrm{n} / \mathrm{a}$ & $\mathrm{B}-\mathrm{O}$ & B-S \\
\hline \multirow[t]{2}{*}{ Coil 2011 Lateral } & 0.02 & -0.04 & -0.01 & -0.19 & 0.01 & 0.03 & $\mathrm{n} / \mathrm{a}$ & 0.09 & -0.13 \\
\hline & $(-0.15-0.18)$ & $(-0.13-0.04)$ & $(-0.23-0.21)$ & $(-0.29--0.09)$ & $(-0.20-0.21)$ & $(-0.09-0.16)$ & & $(-0.04-0.21)$ & $(-0.26--0.00)$ \\
\hline \multirow[t]{2}{*}{ Coil 2011 Ventral } & -0.06 & 0.08 & -0.01 & -0.05 & 0.02 & 0.10 & $\mathrm{n} / \mathrm{a}$ & 0.16 & 0.04 \\
\hline & $(-0.20-0.08)$ & $(0.01-0.15)$ & $(-0.18-0.15)$ & $(-0.13-0.03)$ & $(-0.14-0.17)$ & $(-0.03-0.24)$ & & $(0.03-0.30)$ & $(-0.10-0.17)$ \\
\hline \multirow[t]{2}{*}{ Coil 2021 Lateral } & 0.21 & 0.07 & -0.12 & -0.06 & $\mathrm{n} / \mathrm{a}$ & -0.21 & $\mathrm{n} / \mathrm{a}$ & -0.12 & -0.38 \\
\hline & $(0.00-0.42)$ & $(-0.06-0.19)$ & $(-0.37-0.13)$ & $(-0.18-0.07)$ & & $(-0.40--0.02)$ & & $(-0.31-0.07)$ & $(-0.57--0.19)$ \\
\hline \multirow[t]{2}{*}{ Coil 2021 Ventral } & -0.06 & 0.03 & 0.05 & -0.07 & $\mathrm{n} / \mathrm{a}$ & -0.03 & $n / a$ & -0.02 & -0.00 \\
\hline & $(-0.13-0.00)$ & $(-0.00-0.07)$ & $(-0.02-0.12)$ & $(-0.11--0.04)$ & & $(-0.11-0.04)$ & & $(-0.09-0.06)$ & $(-0.07-0.07)$ \\
\hline
\end{tabular}

₹ Parameter estimates from linear mixed-effects model with confidence interval in parenthesis; $\mathrm{P}<0.05$ indicated in bold; intercept (int) is the difference between baseline and the condition of interest; motion (mot.) is the proportion of scrubbed voxels; paradigm (para.) accounts for the two different paradigms used with the Coil 2011 dataset.

Table S2. Measures of face-, scene-, and body-selectivity using large lateral and ventral anatomical constraint parcels used by Deen and colleagues ${ }^{\$ 5}$, Related to STAR Methods. 


\begin{tabular}{|c|c|c|c|c|c|c|c|c|c|c|}
\hline $\begin{array}{l}\text { Subject } \\
\text { ID }\end{array}$ & $\begin{array}{c}\text { Ages } \\
\text { (Months) }\end{array}$ & Sex & Visits & $\begin{array}{l}\text { Total } \\
\text { TRs }\end{array}$ & $\begin{array}{l}\text { Coil } \\
2011 \\
\text { TRs }\end{array}$ & $\begin{array}{l}\text { Coil } \\
2021 \\
\text { TRs }\end{array}$ & $\begin{array}{l}\text { Coil } \\
2011 \\
\text { RFX }\end{array}$ & $\begin{array}{l}\text { Coil } \\
2011 \\
\text { ROI }\end{array}$ & $\begin{array}{l}\text { Coil } \\
2021 \\
\text { RFX }\end{array}$ & $\begin{array}{l}\text { Coil } \\
2021 \\
\text { ROI }\end{array}$ \\
\hline inf01 & 2.72 & $\mathrm{~F}$ & 5 & 0 & 0 & 0 & No & No & No & No \\
\hline inf02 & 6.46 & $F$ & 1 & 407 & 0 & 0 & No & No & No & No \\
\hline inf03 & 5.54 & $M$ & 2 & 395 & 156 & 0 & Yes & No & No & No \\
\hline inf04 & $4.23 ; 8.66$ & $\mathrm{~F}$ & 4 & 2155 & 1103 & 0 & Yes & Yes & No & No \\
\hline inf05 & 4.13 & $\mathrm{M}$ & 2 & 559 & 0 & 0 & No & No & No & No \\
\hline inf06 & $4.39 ; 5.90$ & $\mathrm{~F}$ & 8 & 2077 & 287 & 0 & Yes & No & No & No \\
\hline inf07 & 2.95 & $M$ & 1 & 75 & 0 & 0 & No & No & No & No \\
\hline inf08 & 3.7 & $M$ & 3 & 864 & 148 & 0 & Yes & No & No & No \\
\hline inf09 & 6.49 & $\mathrm{~F}$ & 2 & 728 & 229 & 0 & Yes & No & No & No \\
\hline inf10 & $2.59 ; 8.79$ & $M$ & 4 & 1388 & 465 & 0 & Yes & Yes & No & No \\
\hline inf11 & 3.97 & $\mathrm{~F}$ & 3 & 1359 & 414 & 0 & Yes & Yes & No & No \\
\hline inf12 & $2.75 ; 3.90$ & $\mathrm{~F}$ & 5 & 1679 & 182 & 0 & Yes & No & No & No \\
\hline inf13 & $2.82 ; 6.75$ & $M$ & 4 & 1649 & 778 & 0 & Yes & Yes & No & No \\
\hline inf14 & 2.79 & $M$ & 3 & 2294 & 904 & 0 & Yes & Yes & No & No \\
\hline inf15 & 4.23 & $\mathrm{~F}$ & 2 & 374 & 115 & 0 & Yes & No & No & No \\
\hline inf16 & 2.69 & $M$ & 1 & 475 & 0 & 0 & No & No & No & No \\
\hline $\operatorname{inf17}$ & 3.87 & $M$ & 3 & 689 & 0 & 0 & No & No & No & No \\
\hline inf18 & $4.59 ; 8.85$ & $M$ & 3 & 1456 & 337 & 0 & Yes & Yes & No & No \\
\hline inf19 & 4.89 & $M$ & 2 & 96 & 0 & 0 & No & No & No & No \\
\hline inf20 & $6.75 ; 8.62$ & $M$ & 3 & 1288 & 791 & 0 & Yes & Yes & No & No \\
\hline inf21 & 4.43 & $M$ & 1 & 294 & 0 & 0 & No & No & No & No \\
\hline inf22 & 4.13 & $\mathrm{~F}$ & 1 & 423 & 0 & 0 & No & No & No & No \\
\hline inf23 & 5.74 & $\mathrm{~F}$ & 2 & 336 & 45 & 0 & Yes & No & No & No \\
\hline inf24 & 5.05 & $\mathrm{M}$ & 1 & 764 & 373 & 0 & Yes & Yes & No & No \\
\hline inf25 & 4.16 & $\mathrm{~F}$ & 2 & 210 & 0 & 0 & No & No & No & No \\
\hline inf26 & 3.11 & $\mathrm{~F}$ & 2 & 954 & 41 & 0 & Yes & No & No & No \\
\hline inf27 & 4.43 & $\mathrm{M}$ & 1 & 0 & 0 & 0 & No & No & No & No \\
\hline inf28 & 6.56 & $M$ & 1 & 752 & 467 & 0 & Yes & Yes & No & No \\
\hline inf29 & 3.67 & $\mathrm{~F}$ & 2 & 894 & 83 & 0 & Yes & No & No & No \\
\hline inf30 & 6.16 & $M$ & 1 & 88 & 0 & 0 & No & No & No & No \\
\hline inf31 & 6.03 & $M$ & 4 & 1419 & 343 & 0 & Yes & Yes & No & No \\
\hline inf32 & 3.25 & $F$ & 2 & 2086 & 506 & 0 & Yes & Yes & No & No \\
\hline inf33 & 5.61 & $\mathrm{~F}$ & 3 & 1611 & 1080 & 0 & Yes & Yes & No & No \\
\hline inf34 & 3.87 & $M$ & 1 & 565 & 114 & 0 & Yes & No & No & No \\
\hline inf35 & 4.46 & $F$ & 1 & 208 & 0 & 0 & Yes & No & No & No \\
\hline inf36 & 2.49 & $\mathrm{~F}$ & 2 & 1585 & 217 & 0 & Yes & Yes & No & No \\
\hline inf37 & 3.08 & $\mathrm{~F}$ & 1 & 0 & 0 & 0 & No & No & No & No \\
\hline inf38 & 4.52 & $\mathrm{~F}$ & 1 & 379 & 0 & 0 & No & No & No & No \\
\hline inf39 & 5.34 & $\mathrm{~F}$ & 2 & 786 & 309 & 0 & Yes & Yes & No & No \\
\hline inf40 & $5.54 ; 9.38$ & $\mathrm{~F}$ & 3 & 1769 & 615 & 441 & Yes & Yes & Yes & Yes \\
\hline inf41 & $4.13 ; 7.90$ & $\mathrm{~F}$ & 2 & 1387 & 335 & 954 & Yes & Yes & Yes & Yes \\
\hline inf42 & 4.75 & $M$ & 1 & 47 & 0 & 0 & No & No & No & No \\
\hline inf43 & 2.79 & $M$ & 2 & 0 & 0 & 0 & No & No & No & No \\
\hline inf44 & 3.02 & $\mathrm{M}$ & 1 & 26 & 0 & 0 & No & No & No & No \\
\hline inf45 & $6.16 ; 7.70$ & $M$ & 3 & 1350 & 583 & 251 & Yes & Yes & Yes & No \\
\hline inf46 & 11.87 & $M$ & 1 & 0 & 0 & 0 & No & No & No & No \\
\hline inf47 & 4.92 & $M$ & 2 & 514 & 300 & 0 & Yes & Yes & No & No \\
\hline inf48 & 9.74 & $M$ & 2 & 762 & 0 & 648 & No & No & Yes & Yes \\
\hline
\end{tabular}




\begin{tabular}{|c|c|c|c|c|c|c|c|c|c|c|}
\hline inf49 & 5.51 & $\mathrm{M}$ & 2 & 462 & 0 & 303 & No & No & Yes & Yes \\
\hline inf50 & 5.97 & $M$ & 1 & 411 & 0 & 271 & No & No & No & Yes \\
\hline inf51 & 5.93 & $M$ & 1 & 170 & 0 & 108 & No & No & No & Yes \\
\hline inf52 & 9.44 & $\mathrm{~F}$ & 1 & 0 & 0 & 0 & No & No & No & No \\
\hline inf53 & 6.62 & $F$ & 2 & 295 & 0 & 56 & No & No & No & No \\
\hline inf54 & 6.98 & $\mathrm{M}$ & 2 & 1123 & 0 & 304 & No & No & Yes & Yes \\
\hline inf55 & 5.18 & $M$ & 1 & 778 & 0 & 731 & No & No & Yes & Yes \\
\hline inf56 & 5.25 & $M$ & 1 & 0 & 0 & 0 & No & No & No & No \\
\hline inf57 & 4.56 & $M$ & 2 & 1383 & 0 & 1009 & No & No & Yes & Yes \\
\hline inf58 & 8.23 & $M$ & 1 & 0 & 0 & 0 & No & No & No & No \\
\hline inf59 & 4.2 & $M$ & 1 & 297 & 0 & 0 & No & No & No & No \\
\hline inf60 & 9.41 & $\mathrm{~F}$ & 1 & 894 & 0 & 603 & No & No & Yes & Yes \\
\hline inf61 & 3.21 & $M$ & 1 & 0 & 0 & 0 & No & No & No & No \\
\hline inf62 & 4.56 & $M$ & 1 & 535 & 0 & 178 & No & No & Yes & No \\
\hline inf63 & 6 & $F$ & 3 & 841 & 0 & 380 & No & No & Yes & Yes \\
\hline inf64 & 5.57 & $M$ & 1 & 355 & 0 & 309 & No & No & Yes & Yes \\
\hline inf65 & 4.43 & $F$ & 1 & 49 & 0 & 0 & No & No & No & No \\
\hline inf66 & $\mathrm{n} / \mathrm{a}$ & $\mathrm{n} / \mathrm{a}$ & 1 & 0 & 0 & 0 & No & No & No & No \\
\hline inf67 & 4 & $\mathrm{~F}$ & 1 & 14 & 0 & 0 & No & No & No & No \\
\hline inf68 & 4 & $F$ & 2 & 516 & 0 & 416 & No & No & Yes & Yes \\
\hline inf69 & 3.15 & $M$ & 1 & 0 & 0 & 0 & No & No & No & No \\
\hline inf70 & 5.48 & $\mathrm{~F}$ & 1 & 77 & 0 & 0 & No & No & No & No \\
\hline inf71 & 4.43 & $F$ & 1 & 548 & 0 & 249 & No & No & Yes & Yes \\
\hline inf72 & 6.03 & $F$ & 1 & 0 & 0 & 0 & No & No & No & No \\
\hline inf73 & 6.26 & $M$ & 1 & 23 & 0 & 0 & No & No & No & No \\
\hline inf74 & 6.72 & $M$ & 3 & 453 & 0 & 183 & No & No & Yes & No \\
\hline inf75 & 4.3 & $M$ & 1 & 758 & 0 & 631 & No & No & Yes & Yes \\
\hline inf76 & 6.43 & $M$ & 2 & 622 & 0 & 286 & No & No & Yes & Yes \\
\hline inf77 & 5.44 & $F$ & 1 & 28 & 0 & 0 & No & No & No & No \\
\hline inf78 & 3.44 & $\mathrm{~F}$ & 1 & 216 & 0 & 72 & No & No & No & No \\
\hline inf79 & 2.98 & $F$ & 2 & 778 & 0 & 221 & No & No & Yes & Yes \\
\hline inf80 & 3.77 & $F$ & 1 & 672 & 0 & 604 & No & No & Yes & Yes \\
\hline inf81 & 5.38 & $\mathrm{~F}$ & 2 & 827 & 0 & 87 & No & No & Yes & No \\
\hline inf82 & 2.1 & $F$ & 2 & 300 & 0 & 118 & No & No & Yes & No \\
\hline inf83 & 4.43 & $F$ & 1 & 566 & 0 & 511 & No & No & Yes & Yes \\
\hline inf84 & 3.67 & $F$ & 2 & 386 & 0 & 66 & No & No & No & No \\
\hline inf85 & 3.21 & $M$ & 1 & 628 & 0 & 295 & No & No & Yes & Yes \\
\hline inf86 & 3.97 & $M$ & 1 & 0 & 0 & 0 & No & No & No & No \\
\hline inf87 & 4.79 & $\mathrm{~F}$ & 1 & 308 & 0 & 0 & No & No & No & No \\
\hline \multicolumn{11}{|c|}{$\begin{array}{l}\text { Columns from left to right indicate: (1) Subject ID, (2) age at first visit for each timepoint in } \\
\text { months (timepoint is defined as a 30-day window) - two ages indicate two timepoints, (3) sex } \\
\text { reported, (4) total number of two-hour scan sessions scheduled, (5) total number of TRs } \\
\text { collected across all visits, (6) total number of TRs collected on Coil } 2011,(7) \text { total number of } \\
\text { TRs collected on the Coil 2021, (8) if the subject had enough data (at least } 96 \text { TRs) to be } \\
\text { included in the Coil } 2011 \text { group random effects analysis, (9) if the subject had enough data to } \\
\text { be included in the fROI analysis, (10) if the subject had enough data (at least } 96 \text { TRs from a } \\
\text { single acquisition sequence) to be included in the Coil } 2021 \text { group random effects analysis, (11) } \\
\text { if the subject had enough data to be included in the Coil } 2021 \mathrm{fROl} \text { analysis. }\end{array}$} \\
\hline
\end{tabular}

Table S3. Subject Collection information, Related to STAR Methods. Data was collected from individual subjects, often on multiple days. All data collected within one month is considered a single timepoint. Age reported is the age of the subject at the first visit. For full details of volume inclusion, group random effects, and $\mathrm{fROI}$ inclusion criteria (see Methods). 


\section{Supplemental References}

S1. Rajimehr R, Devaney KJ, Bilenko NY, Young JC, Tootell RBH. The "parahippocampal place area" responds preferentially to high spatial frequencies in humans and monkeys. PLoS Biol. 2011;9(4).

S2. Nasr S, Echavarria CE, Tootell RBH. Thinking Outside the Box: Rectilinear Shapes Selectively Activate Scene-Selective Cortex. J Neurosci. 2014;34(20):6721-35.

S3. Yue X, Robert S, Ungerleider LG. Curvature processing in human visual cortical areas. Neuroimage. 2020;222(August).

S4. Yue X, Pourladian IS, Tootell RBH, Ungerleider LG. Curvature-processing network in macaque visual cortex. Proc Natl Acad Sci U S A. 2014;111(33).

S5. Deen B, Richardson H, Dilks DD, Takahashi A, Keil B, Wald LL, et al. Organization of high-level visual cortex in human infants. Nat Commun. 2017;8(13995):1-10.

S6. Keil B, Alagappan V, Mareyam A, McNab JA, Fujimoto K, Tountcheva V, et al. Size-optimized 32-channel brain arrays for 3 T pediatric imaging. Magn Reson Med. 2011 Dec 1;66(6):177787.

S7. Zapp J, Schmitter S, Schad LR. Sinusoidal echo-planar imaging with parallel acquisition technique for reduced acoustic noise in auditory fMRI. J Magn Reson Imaging. 2012;36(3):5818.

S8. Ghotra A, Kosakowski HL, Takahashi A, Etzel R, May MW, Scholz A, et al. A size-adaptive 32channel array coil for awake infant neuroimaging at 3 Tesla MRI. Magn Reson Med. 2021;86(3):1773-85. 